\title{
A Review of Heritage Building Information Modeling (H-BIM)
}

\author{
Facundo José López ${ }^{1, *(1)}$, Pedro M. Lerones ${ }^{2}$, José Llamas ${ }^{2}$ (D) , Jaime Gómez-García-Bermejo ${ }^{3}$ (D) \\ and Eduardo Zalama ${ }^{3}$ \\ 1 DISA, University of Valladolid, 47011 Valladolid, Spain \\ 2 Cartif foundation, Parque tecnológico de Boecillo, 47151 Valladolid, Sapin; \\ pedler@cartif.es (P.M.L.); joslla@cartif.es (J.L.) \\ 3 ITAP, University of Valladolid, 47011 Valladolid, Spain; jaigom@eii.uva.es (J.G.-G.-B.); \\ ezalama@eii.uva.es (E.Z.) \\ * Corresponding author: arq.lopezfacundo@gmail.com; Tel.: +34-610-687-429
}

Received: 28 March 2018; Accepted: 3 May 2018; Published: 5 May 2018

\begin{abstract}
Many projects concerning the protection, conservation, restoration, and dissemination of cultural heritage are being carried out around the world due to its growing interest as a driving force of socio-economic development. The existence of reliable, digital three-dimensional (3D) models that allow for the planning and management of these projects in a remote and decentralized way is currently a growing necessity. There are many software tools to perform the modeling and complete three-dimensional documentation of the intervened monuments. However, the Architecture, Engineering and Construction (AEC) sector has adopted the Building Information Modeling (BIM) standard over the last few decades due to the progress that has been made in its qualities and capabilities. The complex modeling of cultural heritage through commercial BIM software leads to the consideration of the concept of Heritage BIM (H-BIM), which pursues the modeling of architectural elements, according to artistic, historical, and constructive typologies. In addition, H-BIM is considered to be an emerging technology that enables us to understand, document, advertize, and virtually reconstruct the built heritage. This article is a review of the existing literature on $\mathrm{H}$-BIM and its effective implementation in the cultural heritage sector, exploring the effectiveness and the usefulness of the different methodologies that were developed to model families of elements of interest.
\end{abstract}

Keywords: cultural heritage documentation; BIM; H-BIM; H-BIM literature review; as-is model H-BIM; 3D heritage modeling; point clouds; Laser scanner

\section{Introduction and Aims}

According to UNESCO, the World Heritage is divided into Natural, Cultural, and Underwater Heritage. In turn, Cultural Heritage $(\mathrm{CH})$ is divided into two broad categories, tangible cultural heritage and intangible cultural heritage. All of them reflect universal values that must be a legacy for future generations [1,2]. Tangible cultural heritage, particularly immovable assets (monuments, archaeological sites, and so on), is the main subject of application in the new approaches. However, there is a decided lack of documentation and technical information in many existing historic buildings [3,4]. This can result in inefficient project management, loss of time, and increased costs in maintenance or updating processes [5]. So, a structured digital three-dimensional (3D) model as part of the architectural heritage improvement process is an urgent need, nowadays. Moreover, the digital 3D model must be converted into a crucial reference frame for the understanding and monitoring of 
documentation [6,7], thus creating a data source (graphics and semantics) that is suitable for assisting in conservation, restoration, and reconstruction projects [8].

3D scanning and photogrammetry technologies are particularly relevant for accelerating spatial data collection from existing buildings, as well as for rapid intervention conditions are dangerous. Laser scanners, in particular, provide a precise geometric reproduction of three-dimensional objects in a short time, in the form of millions of points, with geometric coordinates ( $\mathrm{X}, \mathrm{Y}, \mathrm{Z})$ [9]. Moreover, color information can also be incorporated or mapped by using internal or external calibrated cameras [10]. A series of steps, such as cleaning and filtering the "noise" of the point cloud, is required before the raw point cloud can be used, thus obtaining a final global cloud that aims to preserve the original complexity of the documented heritage.

The processed point clouds can be incorporated into Building Information Modeling (BIM) platforms, which have been adopted by scientific communities and the Architecture, Engineering, and Construction (AEC) sector in recent years as a new paradigm for the design, documentation, and digital management of existing assets, especially of the built historical monuments [11,12].

There are currently many BIM platforms that are used by experts to perform the modeling, virtual visualization, and management of the integral and incremental knowledge of architectural heritage. However, it is important to note that the libraries and tools of the BIM platforms focus on the design and construction of new buildings with simple, regular, and standardized objects $[13,14]$. For this reason, the virtual and detailed reconstruction of cultural-historical heritage has revealed some limitations of BIM platforms, such as the unavailability of historical parametric object libraries and the lack of tools for managing complex, irregular, and uncertain shapes that are obtained from point clouds.

Moreover, obtaining parametric 3D models of the building elements from the point clouds is considered a time-consuming process. Therefore, according to Murphy et al., (2009) [15] and Volk et al., (2014) [16], once the parametric objects are modeled using the architectural historical documentation and the laser scanning data, libraries of the modeled elements should be generated, thus encapsulating the concept of Heritage Building Information Modeling (H-BIM). These new H-BIM libraries, which work as a plug-in for BIM within the general framework of "Smart heritage", allow for the design, rehabilitation, reconstruction, management, and maintenance processes of architectural heritage to become simpler, clearer, and quicker during the rest of its life cycle [17].

The growing necessity to recover and digitally represent heritage buildings [18], and the limitations of software to automate the direct transformation of the point cloud to solid components, has led the experts to face the challenge of choosing different BIM platforms that will be used to manage the implementation of the semi-automatic design and the reconstruction processes of virtual modeling. These processes are possible thanks to a common data structure called Industry Foundation Classes (IFC), which was developed by BuildingSMART $[19,20]$. This structure guarantees the existence of collaborative interventions, as well as the interoperability, exchange, and storage of relevant data between experts and different BIM software platforms [21,22]. Therefore, it is considered that the developed H-BIM components can be shared and used by all of those experts that are interested in the topic.

It should be noted that the semi-automatic construction of H-BIM models is a current topic in R\&D. This is demonstrated in the context of the EU H2020 research framework program under two leading projects: DURAARK (Durable Architectural knowledge: http://duraark.eu/) and INCEPTION (Inclusive cultural heritage in Europe through 3D semantic modeling: www.inception-project.eu). The INCEPTION project, in particular, includes a special focus on H-BIM graphic, semantic, and topological interoperability, in which the graphic and semantic information of interest in Cultural Heritage, its sources and suppliers, the technologies and formats, and the applicable directives have all been defined and agreed as an object of research.

In short, this paper addresses a comprehensive review that includes 131 recent publications on the implementation of BIM for the maintenance, diagnosis, management, or complete parametric 
modeling "as-is model" of existing buildings, specifically those belonging to the cultural heritage $(\mathrm{CH})$. In addition, the most relevant methods, tools, and technologies for the acquisition, management, and exchange of information in BIM are also described. On the other hand, the scope includes the collection of data and knowledge concerning H-BIM/BIM and other software used for the 3D modeling and information management of $\mathrm{CH}$. However, it ignores considerations concerning construction programming, cost estimation, analyses and simulations, residual management, and demolition, due to the different requirements and the fact that most of the bibliographies mainly deal with new buildings $[23,24]$.

The aim this bibliographic review is to develop an H-BIM conceptual framework based on this information and to highlight its implementation and functionality in the reconstruction, documentation, management, or maintenance projects of the world's architectural heritage. In this context, the present research will be useful for understanding the potentialities and difficulties of the most influential methodologies in the processes of the parametric modeling of cultural heritage.

\section{Methodology and Literature Review}

This research exhibits a critical review of the scientific and technical literature that will allow for us to identify, evaluate, and understand current trends and gaps in knowledge concerning the documentation and 3D virtual modeling of existing buildings. In addition, this research will be useful for those researchers that are involved in the implementation of BIM for modeling historic buildings and for H-BIM modeling.

According to Wong \& Zhou, 2015 [25] and Heradio et al., 2016 [26], due to the large flow of existing studies on the aforementioned subject, a filter or bibliometric study is required to recognize the most influential publications, the evolution of the interest in those subjects over time, and the relationship between them. With this purpose, the data collection of the scientific literature was carried out through a search using keywords in the different sources of contributions, such as academic journals, proceedings of congresses, regulations, and book sections. The keywords that are covered are "BIM", "BIM for existing buildings", "Cultural Heritage modeling", "H-BIM" "Heritage BIM", "Historic BIM", and "heritage management and documentation as built". In addition, these keywords are grouped according to their theme to improve interpretability [26].

In this context, it is worth clarifying that the search of the scientific contribution sources was carried out through Scopus, ScienceDirect, and Google Scholar. In addition, the BuildingSMART standard committee and some sections of software providers have been revised to obtain information beyond the academic publications. In relation to the scientific contributions found, those with the highest frequency of the key words used and the highest number of citations have been selected and examined.

A total of 131 contributions that were published between 2007 and 2018 were analyzed, of which 87 correspond to papers in journals with an international impact, 23 to proceedings of congresses, five to data obtained from sections of books, two to international regulations, and 14 to Internet sources. Table 1 shows how the publication flow is distributed.

As shown in Figure 1, 38 papers, focus on the implementation of BIM or BIM functionalities in existing buildings, 36 papers include the word ' $\mathrm{H}$-BIM' in the title, abstract, keywords, or main text, and 19 papers do not mention BIM or do not explicitly build BIM models, but they do deal with the 3D virtual modeling of existing buildings (CAD models, 3D MAX, Rhino, Skp., Semantic Web services, etc.). In addition, 13 documents deal with issues that are related to data capture and processing, while the nine remaining publications focus on other issues (heritage, data exchange, demolition, etc.). In addition, Figure 1 shows how the flow of publications has evolved, intensifying over the years. Furthermore, according to Table 1, the largest number of selected publications is from "Automation in Construction (AIC)", "The International Archives of Photogrammetry, Remote Sensing and Space Information Sciences (ISPRS)", "Journal of Cultural Heritage", "Survey Review", and the "IEEE Digital Heritage International Congress". 
Table 1. Flow of publication.

\begin{tabular}{|c|c|c|c|c|}
\hline & Journals & Main Topics & Impact Factor * & Number of Selected Publications \\
\hline 1 & Journal of Cultural Heritage & Material science, Multidisciplinary & $1.838(\mathrm{JCR})$ & 8 \\
\hline 2 & International Journal of Architectural Heritage & Construction \& Building Technology & 1.053 (JCR) & 3 \\
\hline 3 & Advanced Engineering Informatics & Computer Science, AI & 2.680 (JCR) & 2 \\
\hline 4 & Automation in Construction & Construction \& Building Technology & 2.919 (JCR) & 12 \\
\hline 5 & Computer-Aided Civil and Infrastructure Engineering & Construction \& Building Technology & 5.786 (JCR) & 1 \\
\hline 6 & Studies in Conservation & Analytical & 0.578 (JCR) & 1 \\
\hline 7 & International Journal of Project Management & Management & 4.034 (JCR) & 1 \\
\hline 8 & Structural Survey & Buildings and Construction & 0.28 (SJR) & 2 \\
\hline 9 & Procedia Engineering & Engineering & 0.74 (CiteScore) & 1 \\
\hline 10 & International Journal of Architectural Computing & Computer-aided Architectural design & $0.122(\mathrm{SJR})$ & 2 \\
\hline 11 & ISPRS Journal of Photogrammetry and Remote Sensing & Remote sensing & 6.387 (JCR) & 23 \\
\hline 12 & Survey Review & Remote sensing & 0.929 (JCR) & 5 \\
\hline 13 & Computers in Industry & Computer Science & 2.691 (JCR) & 1 \\
\hline 14 & Digital Applications in Archaeology and Cultural Heritage & 3D digital models of the cultural heritage & 0.252 (SJR) & 3 \\
\hline 15 & DISEGNARE CON & Heritage Architecture & - & 3 \\
\hline 16 & Journal of Computing in Civil Engineering & Computer Science, Engineering & 2.310 (JCR) & 1 \\
\hline 17 & Computers Environment and Urban Systems & Environmental Science & 2.659 (JCR) & 1 \\
\hline 18 & Information and Software Technology & Information Systems, Software Engineering, & 2.694 (JCR) & 1 \\
\hline 19 & WIT Transactions on The Built Environment & Buildings and Construction & 0.12 (SJR) & 4 \\
\hline 20 & Science China Information Sciences & Engineering, Material Science & 1.719 (JCR) & 1 \\
\hline 21 & Archives of Computational Methods in Engineering & Computer Science, Interdisciplinary Applications & 5.061 (JCR) & 1 \\
\hline 22 & Journal of Information Technology in Construction & Buildings and Construction & 0.352 (SJR) & 2 \\
\hline 23 & Leadership and Management in Engineering & Civil and Structural Engineering & 0.144 (SJR) & 1 \\
\hline 24 & Virtual Archaeology Review & Conservation, Documentation, 3D surveying & $0.1+3(0 \mathrm{NA})$ & 2 \\
\hline 27 & CSE-City Safety Energy & & - & 1 \\
\hline 28 & SCIRES-IT-SCIentific RESearch and Information Technology & $\begin{array}{l}\text { Cultural and environmental Heritage } \\
\text { documentation }\end{array}$ & - & 2 \\
\hline \multicolumn{5}{|c|}{ Congress Proceedings } \\
\hline 1 & \multicolumn{2}{|c|}{ Annual Conference of the Association for Computer Aided Design in Architecture } & \multicolumn{2}{|r|}{1} \\
\hline 2 & \multirow{2}{*}{\multicolumn{2}{|c|}{ eCAADe Conference }} & \multicolumn{2}{|r|}{1} \\
\hline 3 & & ICB World Building Congress & \multicolumn{2}{|r|}{1} \\
\hline 4 & \multicolumn{2}{|c|}{ International Conference on Computing in Civil and Building Engineering } & \multicolumn{2}{|r|}{2} \\
\hline 5 & \multicolumn{2}{|c|}{ International Conference on Big Data (Big Data) IEEE } & \multicolumn{2}{|r|}{1} \\
\hline 6 & \multicolumn{2}{|c|}{ Digital Heritage International Congress (DigitalHeritage) IEEE } & \multicolumn{2}{|r|}{7} \\
\hline 7 & \multicolumn{2}{|c|}{$\begin{array}{l}\text { CIB W78 Conference } \\
\text { C }\end{array}$} & \multicolumn{2}{|r|}{1} \\
\hline 8 & \multicolumn{2}{|c|}{ International Building Control Conference } & \multicolumn{2}{|r|}{1} \\
\hline 9 & \multicolumn{2}{|c|}{ International Conference on Virtual Systems and Multimedia } & \multicolumn{2}{|r|}{1} \\
\hline 10 & & \multicolumn{2}{|r|}{2} \\
\hline 11 & \multicolumn{2}{|c|}{ International Symposium on Automation and Robotics in Construction (ISARC) } & \multicolumn{2}{|r|}{1} \\
\hline 12 & \multirow{2}{*}{\multicolumn{2}{|c|}{ Digital Documentation International Conference }} & \multicolumn{2}{|r|}{1} \\
\hline 13 & & & & 1 \\
\hline 14 & International Conferer & f Science and Computation ICCSA & & 1 \\
\hline
\end{tabular}


Table 1. Cont.

\begin{tabular}{|c|c|c|}
\hline \multicolumn{2}{|r|}{ Books } & \\
\hline 1 & Recording, Documentation, and Information Management for the Conservation of Heritage Places & 1 \\
\hline 2 & Heritage Building Information Modelling & 1 \\
\hline 3 & Computational Modeling of Objects Presented in Images & 1 \\
\hline 4 & Handbook of Research on Emerging Technologies for Digital Preservation and Information Modeling & 1 \\
\hline 5 & BIM Handbook: A Guide to Building Information Modeling for Owners, Managers, Designers, Engineers and Contractors & 1 \\
\hline \multicolumn{3}{|c|}{ Internet Sources } \\
\hline 1 & ClearEdge 3D & 1 \\
\hline 2 & IMAGINiT & 1 \\
\hline 3 & Graphisoft & 1 \\
\hline 4 & Tekla & 1 \\
\hline 6 & BuildingSMART & 3 \\
\hline 7 & Autodesk & 1 \\
\hline 8 & DAYSIM & 1 \\
\hline 9 & SKETCHUP & 1 \\
\hline 10 & DURAARK & 1 \\
\hline 11 & Innovmetric & 1 \\
\hline \multirow[t]{2}{*}{12} & Meshlab & 1 \\
\hline & Regulations & 2 \\
\hline
\end{tabular}

* Impact Factor according to: (JCR) InCites Journal Citation Reports, (SJR) Scimago Journal \& Country Rank, CiteScore and Scopus. 
In particular, most of the scientific contributions that were analyzed describe the combination of new data acquisition technologies (laser scanner and photogrammetry) with BIM platforms to achieve virtual and parametric modeling of architectural heritage. However, only a few documents deal with the automation of the reverse engineering process, with or without BIM, as well as the processes of interoperability, management, documentation, and maintenance of the "as-is model" building.

It is important to highlight that the main difference that is presented in this research with regard to the research of Volk et al., 2014 [16] and Bruno et al., 2018 [27] is that this research focuses on the description of the H-BIM library as a possible tool for projects of reconstruction, documentation, management, or maintenance of $\mathrm{CH}$.

The paper is structured, as follows. This section has shown the implemented method to collect and examine the scientific publications that are related to the methodology, functionality, and implementation of H-BIM. The next section (Section 3) defines the approaches for the surveying, acquisition and processing of geometric data of the analyzed building. In addition, it also explains some aspects related to 3D geometric modeling from the use of point clouds. In Section 4, BIM is defined in a broader sense to ensure its terminology. In addition, the functionalities and tools that are available in BIM are briefly described. Once the general background regarding the virtual modeling of existing buildings has been set out, Section 5 describes the concept of H-BIM as the first measure. Subsequently, it focuses on the evolution and the implementation of H-BIM in the processes of the documentation, management, and modeling of architectural heritage. The last section discusses the issues and limitations that were found during the analysis and also describes the conclusions of this research.

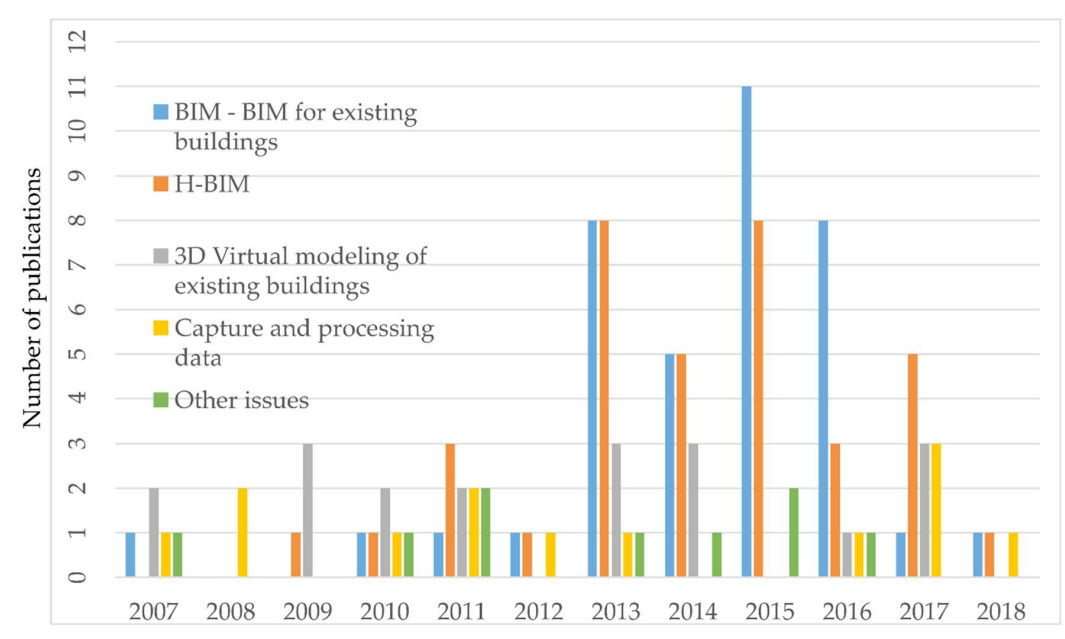

Figure 1. This figure shows the most used approaches in the analyzed publications. How the flow of publications has evolved, intensifying over the years, is also noticeable. Source: Own figures.

\section{Data Capture and Processing}

The technological revolution that has been achieved over the last few decades brought with it new technologies that have improved and accelerated the topographic techniques of spatial data acquisition to generate accurate construction information models. In this section, the two most influential techniques nowadays are described: photogrammetry and terrestrial laser scanning (TLS). In addition, the necessary processing steps for the captured data to be used are explained.

Furthermore, in this section, some approaches related to 3D geometric modeling from the use of the point clouds are also explained.

\subsection{Photogrammetry}

Photogrammetry is a precise 3D measurement technique, without contact, which is based on several high-quality images that allow for the collection of semantic and spatial data of a building or 
object to be accelerated [28]. Photogrammetry is a technique based on triangulation, where the lines of vision of cameras, which are located in several places, are joined at a common point in the object. The results obtained with the photographic survey are orthographic images or models of triangulated and textured surfaces.

According to Grussenmeyer, 2008 [29] and Furukawa et al., 2009 [30], the post-processing of photographic reconstruction can be considered to be a great disadvantage. This is because it is a process that generates a great manual effort and consumes a lot of time, especially when the texture of the object is poor and its shape is very complex. In addition, for the images to be used as 2D or 3D models of high precision, processes of intersection of characteristic points and scalability must first be applied to each capture obtained and later combined with precise topographic or empirical measurements [31].

Although the current development of computational intelligence does not allow for complete automation, the combination of photogrammetry with computer vision (basically incorporating Structure for Motion (SfM) algorithms) is beginning to provide accurate results in 3D modeling in cultural heritage [32]. Free and online access to a multitude of quality photographs is becoming an incomparably fast, cheap, and realistic way of capturing reality to virtually reproduce artifacts and buildings [33]. That is why an increasing number of software tools are easily found to reconstruct 3D models from photos as automatically as possible.

\subsection{Laser Scanning Technique}

Laser scanning technologies are adopted for their ability to accelerate the spatial data collection of existing buildings or complex surfaces, as well as for the accuracy and precision of the acquired data. Laser scanners are subdivided into two specific areas, aerial and terrestrial. Each one has a range and precision that is suitable for the use to which it will be destined. In particular, Laser Scanner Technologies (TLS) work via a laser beam that travels towards the area being scanned and back, measuring angles and distances with accuracies from millimeters to centimeters [34] (Figure 2a). In this context, TLS obtain a precise and detailed geometric reproduction of three-dimensional objects in a short time [35], in the form of millions of points (a cloud of points), with geometric coordinates (X, Y, Z) (Figure 2b) [9], in a digital environment, with both metric and radiometric information. In addition, three different types stand out among the TLS systems: triangulation, phase difference, and Time of Flight (TOF). Each of these TLS systems are capable of producing point clouds of the objects; however, the accuracy and the density of the obtained point clouds will vary depending on the selected scanner type, as well as the number of scans made (Figure 3) [36].

Currently, TLS play a very important role in a wide range of purposes that can be directly extrapolated to cultural heritage [37], including the follow-up of an intervention [38], defect detection [39], or the reproduction of existing models [40,41]. However, the high cost of these technologies, the need for specialized management and the pre-processing of the information acquired can be considered as challenges and/or disadvantages. It should be taken into account that it is not generally possible to capture all of the geometric information of some objects or external surfaces from a single scanning position, since there may be elements that block the scanner view. For this reason, it is necessary to place the scanner in different positions with respect to the object. The data extracted from the different scans creates partial-point clouds $\{(x i, y i, z i)\}$, and then each one of these point clouds is merged to give rise to a global cloud that will describe the site. This process is known as point cloud registration. In order to perform the registration, a certain overlapping between adjacent points sets (i.e., $20-30 \%$ ) is necessary. In this overlap, several common tie points or targets between point clouds must be identified.

The alignment of point clouds is commonly performed using an Iterative Closest Point (ICP)-based optimization algorithm [42]. The alignment is frequently aided by the user with 3D data editing and processing software. Subsequently, so that the raw point cloud can be used, a series of steps, such as cleaning and filtering the "noise" of the point cloud data, is performed. Cleaning and filtering is 
generally user aided, with specific point cloud handling software (i.e., Polyworks ${ }^{\circledR}$ ) [43], as scene interpretation is necessary (e.g., clean points from trees, people, or outliers).

Alternatively, polygon surface meshing can be used as the data processing method. With this method, a surface that is composed of triangles is created on the point cloud. This mesh is edited to fill holes in the cloud, as well as to soften and to reduce the points of the model [44]. The pre-processing of the information is considered to be vital, since the alignment and debugging of the cloud of points is what allows for the captured information to be accurately referenced.

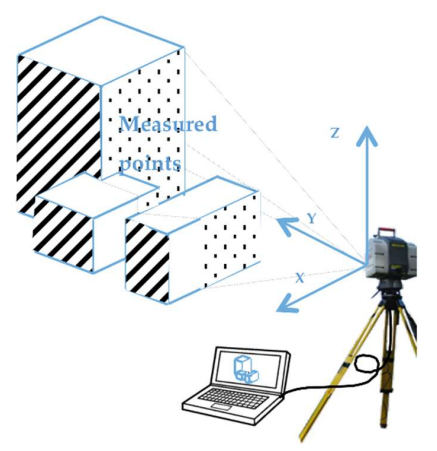

(a)

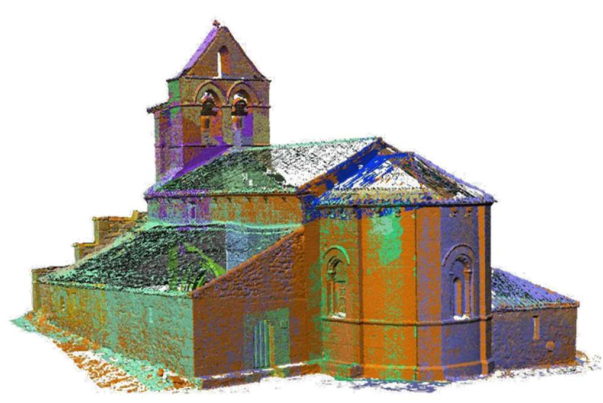

(b)

Figure 2. (a) Laser scanning process to create a point cloud; (b) Georeferenced point cloud, (X, Y, Z). Source: Own figures.
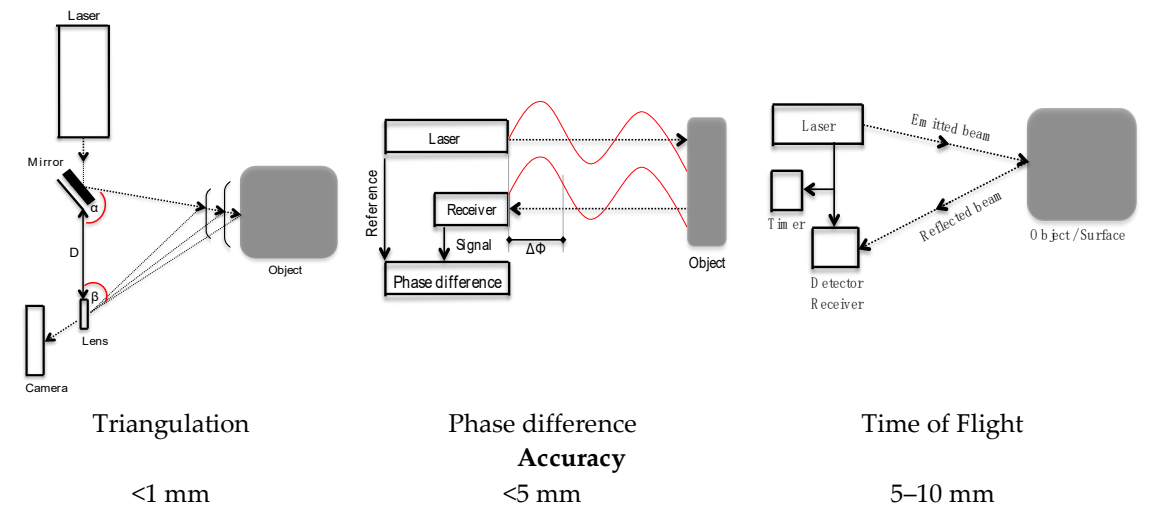

Figure 3. Systems and Accuracy of the terrestrial laser scanning (TLS). Source: Own figures.

\subsection{Point Cloud Approach}

The captured and processed point clouds describe, in detail, the surface of the scanned elements [45,46]. Unfortunately, these point clouds do not contain additional information about the objects whose geometry they represent. Therefore, to obtain geometrical, topological, and semantic attributes, it is necessary to produce 3D geometric models or parametric objects. This 3D modeling can be described as a reverse engineering process. The segmentation and recognition of point clouds currently represent the fundamental steps for identifying the correct surfaces and facilitating the tracing or the modeling of parametric objects. These steps can be carried out semi-automatically or fully automatically through the advances added to BIM platforms, as well as the new algorithms of object recognition and point cloud segmentation [16].

\subsubsection{Semiautomatic Modeling Approach}

The semi-automatic process is guided by the user in the form of adjustments, sections, extractions, and extrusions of faces made on the point cloud. In principle, the process consists of using the design software tools to manually configure a series of levels and sections in the $\mathrm{X}, \mathrm{Y}, \mathrm{Z}$ geometric coordinates 
of the point clouds [47]. The planes and two-dimensional views that detail the geometric profile of the scanned objects are obtained thanks to the sections and levels [48]. In addition, levels and sections are also used as the start and end points of each geometry represented. Finally, these mentioned actions will be used as guides to start the geometric modeling of the scanned architectural components.

This process is valuable for documenting and disseminating information that is related to existing buildings. However, achieving its implementation is a difficult and time-consuming task that requires skilled workers [49]. These problems are mainly due to the orthogonal constraints that are present in a large part of the design software and the high numbers of necessary steps to parametrically model the complex geometries that are present in point clouds.

\subsubsection{Automatic Modeling Approach}

Over the last few years, several commercial and academic research works have investigated the automated reconstruction of existing buildings from point clouds, especially since BIM platforms have gained prominence with their parametric models.

From an academic point of view, the most consolidated methods are found in the investigations of Jung et al., 2014 [50]; Hong et al., 2015 [51]; Wang et al., 2015 [52]; Zheliazkova et al., 2015 [53]; and, Liu, 2016 [54]. These researchers have experimented with algorithms to automatically extract the geometric characteristics of the elements through the segmentation of the point clouds.

In the work of Wang et al., 2015 [52] and Liu, 2016 [54], the region growing plane segmentation algorithm is proposed to divide the raw data into point cloud segments, which are located on the same plane. Subsequently, they introduce a boundary detection algorithm that automatically recognizes the shape, size, and position of the surfaces, thus generating contour polygons for each detected feature. The approaches of Jung et al., 2014 [50] and Hong et al., 2015 [51] use the Random Sample Consensus (RANSAC) algorithm to optimize the automatic segmentation of wall planes in the point clouds and extract the components of each surface. Subsequently, refinement and boundary tracing processes are carried out. The first is done to filter points that do not belong to the planes of interest, while the second is used to model the boundaries of a plane segment. The simplified characteristics of each plane found are used as a reference for the manual modeling of parametric geometries.

The main issue of Zheliazkova et al., 2015 [53] was to use the Open Source Software (OSS) Meshlab $^{\circledR}[55]$ and the Ball-Pivoting algorithm (BPA) to create closed meshes and polygons on the surfaces of the point clouds. They then use commercial software to reconstruct the mesh surface in 3D models. Other algorithms, investigated to identify and classify objects within the point clouds, are those of color recognition with spectral images [56] and those of feature recognition $[49,57,58]$.

In spite of the progress achieved, these analyzed approaches do not automate the entire process of point clouds to BIM (Scan-to-BIM). Therefore, the obtained results will be 2D and 3D CAD surface models, which must still be manually converted into parametric BIM models. In this context, according to Volk et al., 2014 [16], the automatic transformation of complex architectural elements into volumetric and semantic entities is still in its infancy.

From another point of view, the research that was carried out by the commercial software companies has led to the development of new complements or solutions to automate the generation of BIM geometries from point clouds. EdgeWise ${ }^{\circledR}$ was created as an independent complement software for Autodesk Revit. This complement classifies and separates the cloud into uniform surfaces. Subsequently, the software automatically searches for candidates of points between pairs of similar horizontal planes and creates the parametric model that is based on the extracted geometry [59]. Scan-to-BIM ${ }^{\circledR}$, from IMAGINiT Technologies, was also developed as a complement to Autodesk Revit. This complement provides detection algorithms and adjustments for the management of the point clouds [60]. With the detection of points, it automatically creates walls or simple objects surfaces in parametric elements [61]. Other complements that also help with the segmentation, detection, processing, and modeling of architectural elements on the point clouds are Kubit PointSense Buildings and Pointfuse from Arithmetica. 
Having reviewed some of the advances that were achieved by academic and commercial research, we consider that an important leap has been taken towards the automatic modeling of point clouds. However, the Scan-to-BIM automatic process has some limitations in implementation for modeling an "as-is model" building.

One of these limitations is due to the fact that, at present, the reading and interpretation of the qualitative data of a space or object is strictly natural for humans, but very difficult for computers because there are still no "smart algorithms" that are capable of performing this function $[62,63]$.

Other identified limitations relate to the lack of software tools to automatically model point clouds in parametric objects. In addition, the restrictions of the algorithms and software complements used are also considered a limitation. This is because such algorithms or complements are only feasible for the segmentation and the automatic modeling of point clouds that represent plane surfaces or primitive geometries, as they generate erroneous and inaccurate results when trying to represent complex and irregular geometries of the historic buildings.

In this context, it should be noted that no algorithm or complement that automated the "Scan-to-BIM" workflow has yet gained wide acceptance in the AEC community [64]. Therefore, despite the fact that the semi-automatic process is a difficult, time-consuming task, it is currently considered to be the most effective process for documentation projects and the parametric modeling of architectural heritage.

\section{Building Information Modeling (BIM) Approaches}

Building Information Modeling (BIM) has currently become a methodology to integrate the design of buildings, as it achieves a 3D digital representation of the physical, functional, and semantic characteristics of an environment, structure, or existing building [27,65].

BIM platforms are based on components, that is, on stored parametric elements in object libraries. Generally, these stored parametric elements are reusable objects that can contain geometric, semantic, or topological attributes [66,67].

According to Pauwels et al., 2008 [68] and Logothetis et al., 2015 [69], BIM technologies allow for the documentation, generation, importation, or manipulation of three-dimensional models using such parametric information as specifications and technical drawings (2D), geometric properties in a collaborative model (3D), constructive temporary programming (four-dimensional (4D)), the definition of amounts and costs (five-dimensional (5D)), sustainability of the project (six-dimensional (6D)), and maintenance and life cycle management (seven-dimensional (7D)). This acquired information is stored in the BIM database and will allow for the creation of a virtual parametric model that can simulate the characteristics and conditions of each element as if they were real [70]. Generally, in BIM, the level of development (LOD) of the project must be represented, so as to determine the degree of certainty, precision, and richness of the information contained in the modeled element and to estimate the specific use for which this information is destined [71,72].

Additionally, BIM can be defined as a multidisciplinary collaborative work platform, where modifications, management, or communications are shared in real time among the participants involved [73]. This characteristic will allow for the useful data to be recovered at any time, avoiding time wasting and reducing the possibility of errors [74]. The collaborative work is possible thanks to the interoperability of BIM platforms, which is achieved by the development of an open and standardized data structure (standard: ISO 16739), called Industry Foundation Classes (IFC) [19]. IFC facilitates and guarantees the transfer of relevant data between the different BIM authoring software applications [22].

Nowadays, Facility Management (FM) activities related to the operational maintenance of a building are necessary. Therefore, in recent years, an international information exchange and storage standard, called Construction Operations Building Information Exchange (COBie), has been developed [75]. The ability of COBie to support the IFC format makes it the BIM application with the best interoperability that is related to the administration and management of facilities [76,77]. The aforementioned features and functionalities have played a fundamental role in convincing the AEC 
sector that BIM is the most efficient and precise for use in the management, construction, restoration, or maintenance projects of existing buildings (new or historic).

\subsection{BIM to Heritage Buildings}

Nowadays, BIM has evolved significantly in the field of the management and documentation of cultural heritage. It can now represent, in a virtual environment, the actual conservation state of the analyzed buildings.

However, the virtual reconstruction procedure of historical-cultural heritage is not an easy task, because the objects to model consist of components whose heterogeneous, complex, and irregular characteristics and morphologies are not represented in the BIM software libraries. Therefore, it is essential to introduce the historical and technical approaches into the BIM environment, as well as the point clouds, to model the different virtual parametric components and achieve a "BIM as-is model" of the architectural heritage analyzed [78,79].

The parametric design of the building elements from the point cloud is a time-consuming and error-prone manual process, because there are currently no automation or software processes that can ensure a direct change from point cloud to full BIM models $[80,81]$. Therefore, once the 3D virtual models have been created, the libraries of the parametric elements should be generated under the concept of H-BIM.

\subsection{BIM Platforms Groups}

In practice, the most specialized BIM platforms, which can be used to carry out the modeling, maintenance or rehabilitation of architectural heritage, are classified into three different toolsets:

- 3D Modelers: Tools for the design of solid parametric models, able to model a real building virtually.

- 3D Viewers: Spatial display tools for models.

- Analyzers: Tools used to analyze the 3D models, generally by means of external-to-BIM platforms.

In addition, BIM tools are classified into commercial, free, and open-source, depending on the legal use governing each software.

The following sections review some representative BIM software for cultural heritage. Information (functionality, tools, object structure, interoperability, OSS, and link) about these software tools are summarized in (Table 2).

\subsubsection{D Modelers}

1. ArchiCAD (Graphisoft): This is a BIM platform, so it allows for users to work with objects and model them with parametric data. In addition, the use of the open-source scripting language Geometric Description Language (GDL) allows for the creation of any type of object and the storage of these objects in the program's internal libraries, thus permitting them to be reused or modified in the future. This platform can import and export DWG, DXF, and SketchUp files; it also provides interoperability with other BIM platforms through the use of IFC $[82,83]$. ArchiCAD is considered to be a commercial BIM platform, due to its legal use.

2. Tekla Structures: This commercial BIM platform is used for the detailed design, cutting, manufacturing, and assembly of all types of structures for construction. High complexity 3D models can be created and managed in real time. In addition, this software is an open solution that can import models from other BIM applications using IFC, thus supporting standardization and interoperability. It also supports DWG, CFI, DGN, DXF, CIS/2, DTSV, and SDNF files [84].

3. Bentley System: This is a commercial BIM platform, which is subdivided into several modules. This platform is used to address all AEC industry aspects. The Bentley platform consists of a set of applications and services based on open-platform, providing solutions for the entire infrastructure lifecycle. This platform is able to link IFC, DWG, DGN, Dxf, and PDF files. In addition, it can open and manipulate point cloud files $[85,86]$. 
4. Revit Autodesk: This is an efficient BIM platform to accurately model regular and irregular surfaces, as well as geometric anomalies of the different elements. This software has a changing parametric behavior that helps to quickly construct and change elements into a 3D model. Moreover, this platform generates construction documents with a high level of quality and flexibility. The Revit platform provides interoperability between different software applications through the use of IFC files [87]. In addition, it is able to link DWG, DGN, Dxf, Sat, and SKP files, and it is also a useful tool to open and manipulate point clouds that are stored in .txt, .RCP, or .rcs files. Moreover, the Revit platform allows for users to add new functions or add-ins from the application programming interface (API), programming languages that could be used to create add-ins written in $\mathrm{C}++, \mathrm{C}$ \# and Python [88]. Autodesk Revit is considered to be a commercial BIM platform, due to its legal use. Moreover, it offers a free student version for three years.

\subsubsection{D Viewers}

1. Tekla BIMsight: This is a free BIM application that is used as a tool to communicate and collaborate in construction projects. This application allows for project participants to visualize the complete model, control crash risk, and identify and solve insertion problems. It also allows for the information that is collected to be shared, using the same BIM platform. Tekla BIMsight is compatible with all other BIM platforms because it supports the IFC files [84].

2. Navisworks Freedom: This tool allows the coordination, simulation and optimization of constructive programming; Navisworks Freedom can also describe the building changes through time and allows an integral revision of the entire building. Creating multidisciplinary models, including all kinds of information, prototypes, and digital designs, is possible with this software. All of these skills can be combined into a single integrated project model and published in NWD files. In addition, Navisworks Freedom is a free tool that provides interoperability with other platforms upon IFC files [89].

3. SketchUp: This is a commercial CAD modeling software, used as a program of graphic design and 3D modeling. SketchUP is widely used by the community of architects, engineers, and designers due to the simplicity and precision of its modeling tools [90]. This software is not considered to be a BIM platform, but it does provide interoperability with other platforms because it supports the BIM extensions (SketchUpBIM, ProfileBuilder, Skalp, etc.) and IFC files.

\subsubsection{Analyzers}

1. Ecotect Analysis: This commercial software allows for the creation, visualization and simulation of energetically efficient and high performance building projects. It provides the performance, use and integration of the building energy, water and materials. In addition, Ecotect allows architects and designers to work easily in 3D, applying all the necessary tools for an efficient and sustainable building. Ecotect Analysis software is also interoperable with Revit ${ }^{\circledR}$ Autodesk [91]. New versions of Revit ${ }^{\circledR}$ Autodesk integrate similar functions within their family-tools. Unfortunately, Autodesk stopped offering Ecotect Analysis in 2015. However, the Ecotect Analysis operating is still considered as efficient for building modeling.

2. DAYSIM: This is a free, open-source software that is responsible for analyzing and calculating the availability of natural light and the use of lighting energy in virtual building projects. It is a simulation engine, consisting of a series of command subprograms written in ' $C$ '. In addition, DAYSIM is compatible with Ecotect, Rhinoceros and SketchUP files [92].

3. Energy Plus: This energy simulation program allows AEC professionals to model the energy consumption for heating, cooling, ventilation, lighting, etc., of a complete building. In addition, EnergyPlusTM is an open-source software that allows for the exchange of information with other tools. 
Table 2. Most used platforms in the Architecture, Engineering, and Construction (AEC) industry.

\begin{tabular}{|c|c|c|c|c|c|c|c|c|c|}
\hline & Product Name & Company & Basic Function & Set of Tools & $\begin{array}{c}\text { Parametric } \\
\text { Objects }\end{array}$ & $\begin{array}{l}\text { Database } \\
\text { Structure }\end{array}$ & Interoperability & oss & Web Link \\
\hline & Archicad & Graphisoft & Creating architectural models & 3D Modelers & Yes & A single file & DWG, DXF, IFC, SKP, & No & http://www.graphisoft.com \\
\hline & Tekla & Tekla & $\begin{array}{c}\text { Detailed design of 3D } \\
\text { structures models }\end{array}$ & 3D Modelers & Yes & Several files & $\begin{array}{l}\text { DWG, IFC, DGN, DXF, } \\
\text { CIS/2, DTSV y SDNF }\end{array}$ & No & http://www.tekla.com/la \\
\hline \multirow{3}{*}{ Revit } & Revit Architecture & Autodesk & Creating and reviewing $3 \mathrm{D}$ models & 3D Modelers & Yes & A single file & \multirow{3}{*}{$\begin{array}{l}\text { DWG, DGN, Dxf, Sat, } \\
\text { SKR, IFC, gbXML, } \\
\text { DWG, DGN, Dxf, Sat, } \\
\text { SKP, IFC } \\
\text { DWG, DGN, Dxf, Sat, } \\
\text { SKP, IFC }\end{array}$} & No & http:// www.autodesk.com \\
\hline & Revit Structure & Autodesk & Design and structural review & 3D Modelers & Yes & A single file & & No & http://www.autodesk.com \\
\hline & Revit MEP & Autodesk & Design and review of facilities & 3D Modelers & Yes & A single file & & No & http://www.autodesk.com \\
\hline \multirow[t]{2}{*}{ Bentley } & Bently Architecture & Bentley Systems & Creating and reviewing 3D models & 3D Modelers & Yes & A single file & $\begin{array}{l}\text { IFC, DWG, DGN, Dxf, } \\
\text { PDE, gbXML }\end{array}$ & No & https://www.bentley.com/en \\
\hline & $\begin{array}{l}\text { Bentley Structural Bentley } \\
\text { Facilities Bentley power civil } \\
\text { Bentley Generative Components }\end{array}$ & Bentley Systems & $\begin{array}{l}\text { Analysis and structural detail. } \\
5 \mathrm{D} \text { Materials calculation. }\end{array}$ & 3D Modelers & $\mathrm{Si}$ & A single file & $\begin{array}{l}\text { IFC, DWG, DGN, Dxf, } \\
\text { PDF, gDXML }\end{array}$ & No & https://www.bentley.com/en \\
\hline & SketchUp & Trimble & 3D conceptual modeling design & $\begin{array}{l}\text { Spectators/ surface } \\
\text { modelers }\end{array}$ & No & A single file & DWG, DXF & No & https:// www.sketchup.com \\
\hline & NavisWorks Freedom & Autodesk & 3D Model Display & $\begin{array}{c}\text { Spectators/surface } \\
\text { modelers }\end{array}$ & No & A single file & IFC & Free Open source & http://www.autodesk.com \\
\hline & Ecotect Analysis & Autodesk & $\begin{array}{l}\text { Energy, temperature, water and } \\
\text { carbon emission analysis }\end{array}$ & Analyzers & Yes & A single file & IFC & No & http://www.autodesk.com \\
\hline & DAYSIM & DAYSIM & $\begin{array}{l}\text { Annual illumination calculation. } \\
\text { Natural or electric }\end{array}$ & Analyzers & - & - & SKP, rws, & Free Open source & http://daysim.ning.com/page/program-structure \\
\hline & LifeCycle & $\begin{array}{l}\text { NREL U.S. LCI } \\
\text { integrated }\end{array}$ & $\begin{array}{l}\text { Analysis and calculation of the } \\
\text { environmental impact of the } \\
\text { materials. }\end{array}$ & Analyzers & - & - & - & No & http://www.nrel.gov//cic/ \\
\hline
\end{tabular}




\section{Heritage Building Information Modeling (H-BIM) Approaches}

The H-BIM concept was first used in the work of Murphy et al., 2009 [15], from the Dublin Institute of Technology. According to Murphy et al., 2011 [82] and Dore et al., 2012 [93], H-BIM pursues the modeling and documentation of architectural elements, according to artistic, historical, and constructive typologies. In addition, H-BIM is considered to be a special library of BIM parametric objects that was specifically designed to preserve and manage cultural heritage within the general framework of "smart heritage". Generally, the H-BIM library is built using the manuscripts and historical architectural documentation, laser scanning, photogrammetric techniques, and other data obtained from the physical analysis of the building in question [94].

An H-BIM flow diagram can be seen in Figure 4. The first step, "Knowledge and Information Collection", covers the collection of information related to graphic, semantic, and typological data. Graphic data is obtained from the 3D laser scanning and photogrammetry methods. These methods can provide a set of raw point clouds that spatially demonstrates the visible parts of the surfaces of a building or object. Concerning the semantic and typological data, it is obtained from the technical analysis of the building and also from the manuscripts and historical documentation. This information will allow for materials and traditional constructive rules to be discovered, as well as the past transformations that could have affected the building. In particular, according to Quattrini \& Baleani, 2015 [95] and Quattrini et al., 2017 [96], the use of historical data to model the components of the H-BIM library introduces the opportunity to develop details that are stored behind the surface of the parametric objects regarding their materials and construction components, their cultural and historical memories, as well as their conservation status and maintenance program. It is also possible to enter temporal parametric data to represent the events that occurred throughout the building lifecycle [78]. Therefore, the components of this new library provide a better reading of the analyzed heritage monuments, and could also be used to produce technical conservation documentation (floor plans, views, elevations, sections, cuts, details, perspectives, etc.) and 3D virtual models (display models) in a semi-automatic way. In addition, it is considered that the parametric objects belonging to the H-BIM library allow for transformations and quick changes in shape, in this way achieving the generation of $3 \mathrm{D}$ virtual models of any project with similar character and architectural style, thus approaching a solution to reverse engineering modeling.

In the second step, "Filtering", which is an ontological process, is created to be used as a knowledge base of all the semantic information collected. The ontology can be integrated into three-dimensional object representation through IFC templates, or directly with the BIM platform. On the other hand, the obtained point clouds are aligned, cleaned, and filtered to facilitate their management. Subsequently, two methods (automatic or manual) can be used to parametrically model the point clouds (Scan-to-BIM). As mentioned in Section 3.3.2, the automatic method consists of the automatic segmentation and generation of parametric objects from the point clouds, using specific algorithms and software plug-ins, which is currently feasible only for plane surfaces or primitive geometries. As shown in Figure 4, in the manual method, the filtered point clouds must be directly integrated into the BIM environment.

The third step, "3D parametric modeling", starts upon the point clouds and the semantic data integrated into the BIM platform. For this step, the integrated point cloud is manually segmented and delimited (following rules and historical patterns) in order to recognize the objects to be modeled. Subsequently, the existing BIM library and the externally constructed objects are used to parametrically model the studied object or building.

The resulting models are grouped in an H-BIM library that could support the parametric modeling of architectural buildings belonging to the same historical period. The H-BIM libraries will serve as the basis for the management and interconnection of information with other data sources thanks to the interoperability capacity between BIM platforms. The H-BIM library interoperability facilitates the historical analysis of the structure, energy simulations, time, and cost calculations, and other functions that will improve the way to manage the maintenance and restoration processes of the analyzed 
buildings. In addition, thanks to H-BIM it is possible to understand the materials and construction techniques, as well as help conservation efforts, management, restoration, or reconstruction of heritage buildings that no longer exist or that are not documented.

Another relevant and original segment of the H-BIM research analyzes some crucial unanswered questions about the H-BIM application [97,98]. According to these works, the BIM methodology can hardly be adapted to historical buildings since they exhibit particular and unrepeatable features. A tradeoff between the modeling accuracy of the various elements and the modeling effort must be adopted.

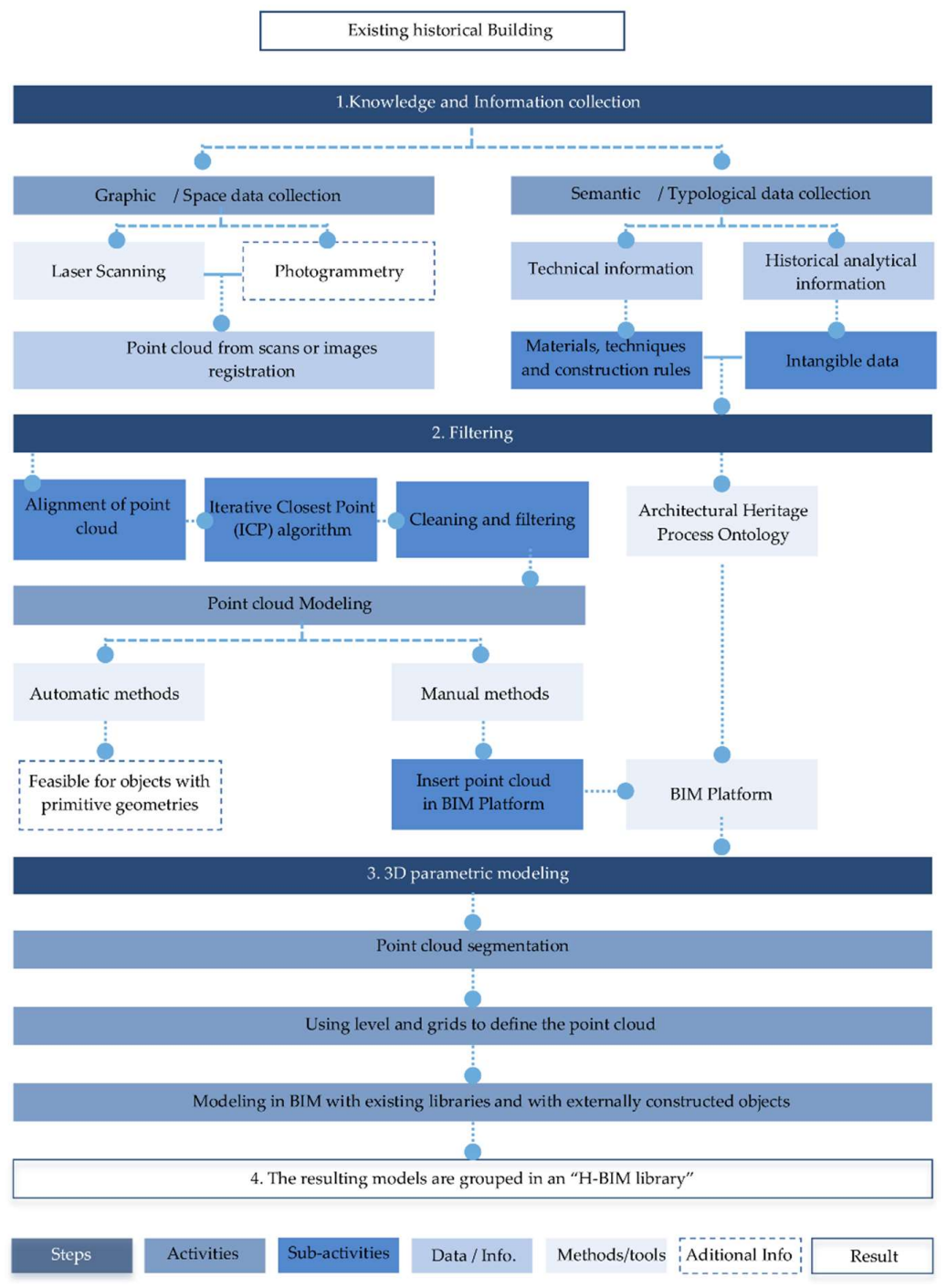

Figure 4. This flow diagram describes the manual construction method of the Heritage Building Information Modeling (H-BIM) library. There are other methods, but they have not been reflected. Source: Own figures.

\subsection{H-BIM Research}

In this section, those documents that have developed different methods and technologies to facilitate the virtual modeling of the existing historical buildings and the parametric H-BIM libraries are described. Table 3 shows the classifications that were made.

According to the analyzed literature, 3D virtual modeling in the architectural heritage field is done in several ways and by using different approaches. These differences allow for research to be grouped according to its purpose, degree of automation, degree of segmentation, etc. Therefore, 
the bibliographic review that is described below has been subdivided into categories according to the tools used in each. The first category corresponds to those researchers who have adopted only the commercial BIM platforms to develop BIM "as-is model" models, and in turn create the parametric H-BIM libraries.

The second category consists of that research that combines commercial BIM platforms with other auxiliary tools for the modeling and development of virtual buildings and H-BIM libraries. Some of these tools do not belong to the BIM world. The third category consists of those works that combine commercial BIM platforms, Open-Source Software (OSS), and non-BIM auxiliary tools with geographic information systems (GIS) software for the modeling and storage of the 3D models. Finally, the fourth category represents those documents that do not use BIM platforms for modeling heritage monuments. The created categories can be seen in Figure 5.

The analysis of the current literature on the virtual modeling of existing buildings has demonstrated the benefits of the use of BIM and H-BIM for the preservation, management, or parametric modeling of cultural heritage $(\mathrm{CH})$.

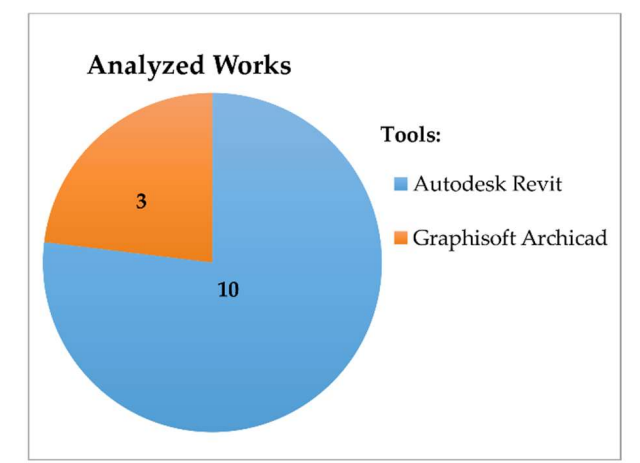

First Category

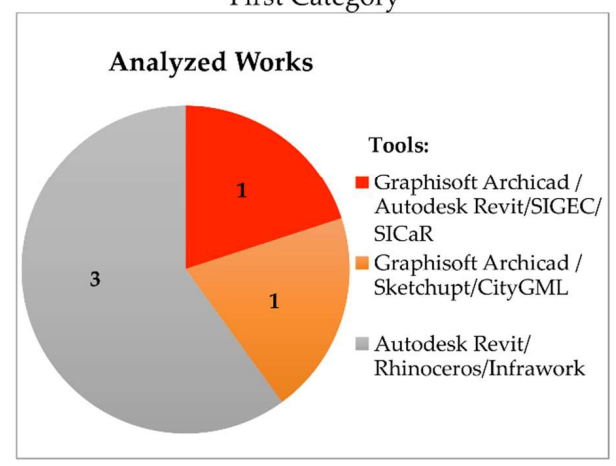

Third Category

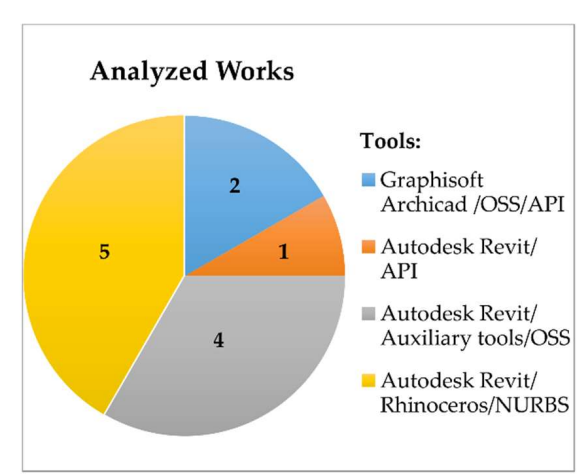

Second Category

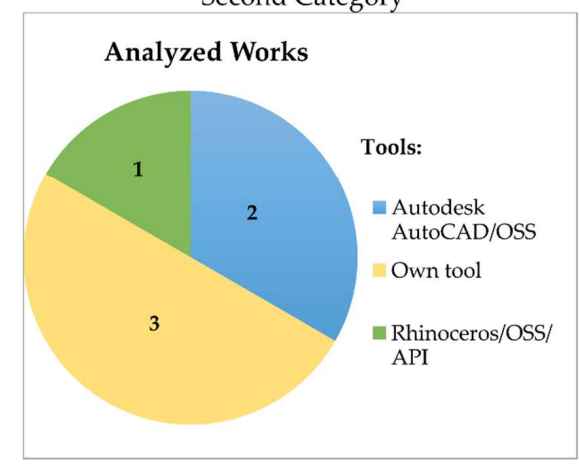

Fourth Category

Figure 5. Categories classification. Source: Own figures. 
Table 3. Current approaches and tools used in the modeling of historic buildings.

\begin{tabular}{|c|c|c|c|c|}
\hline Reference & Case Study & Category & Software & Summary Methodology \\
\hline (Del Giudice \& Osello, 2013) & $\begin{array}{l}\text { The old thermal power plant of Politecnico di } \\
\text { Torino, Italy }\end{array}$ & \multirow{5}{*}{ First category/Only BIM Tools } & Autodesk Revit & $\begin{array}{l}\text { Creates grids to check consistency between } \\
\text { point clouds and historical data. They also } \\
\text { model 4D }\end{array}$ \\
\hline (Lòpez et al.; 2017) & Santa Maria la real de Mave church, Spain & & Autodesk Revit & $\begin{array}{l}\text { Creates parametric components by modifying } \\
\text { and developing new Revit families }\end{array}$ \\
\hline (Brumana et al., 2013) & The church of St. Maria, Italy & & $\begin{array}{l}\text { Autodesk Revit, Autodesk Green } \\
\text { Building Studio }\end{array}$ & $\begin{array}{l}\text { Architectural components are divided into } \\
\text { hierarchies and typology. The final product } \\
\text { carries out an energy analysis }\end{array}$ \\
\hline (Ma et al., 2015) & $\begin{array}{l}\text { The Huji Temple, traditional Taiwan wooden } \\
\text { structure, Taiwan }\end{array}$ & & Autodesk Revit & $\begin{array}{l}\text { Creates a workflow methodology to repair } \\
\text { historical constructions }\end{array}$ \\
\hline (Adami et al., 2016) & $\begin{array}{l}\text { Varius type of Churches of the province of } \\
\text { Mantua, Italy }\end{array}$ & & Autodesk Revit, & $\begin{array}{l}\text { Examines the difficulty for rehabilitating } \\
\text { damaged churches }\end{array}$ \\
\hline (Dore et al., 2015) & The Four Courts of Dublin, Ireland & \multirow{5}{*}{$\begin{array}{l}\text { Second category/BIM/OSS and } \\
\text { auxiliary tools }\end{array}$} & $\begin{array}{l}\text { 3D “RULED” plug-in, Graphisoft } \\
\text { ArchiCAD }\end{array}$ & $\begin{array}{l}\text { Creates an H-BIM library using point cloud and } \\
\text { historical data. }\end{array}$ \\
\hline (Nieto et al., 2016) & The Pavilion of Charles V, Seville, Spain & & Graphisoft ArchiCAD, GDL & Creates an H-BIM library \\
\hline (Oreni et al., 2013, 2014a, 2014b) & $\begin{array}{l}\text { Types of wooden vaults and bean floors and the } \\
\text { Basilica di Santa Maria di Collemaggio, Italy }\end{array}$ & & $\begin{array}{l}\text { Autodesk Revit, Rhinoceros + NURBS } \\
\text { plug-in, MIDAS, AutoCAD. }\end{array}$ & $\begin{array}{l}\text { Uses point clouds and photogrammetry. } \\
\text { Subsequently extracts the NURBS curves and } \\
\text { creates the 3D models surfaces }\end{array}$ \\
\hline (Quattrini et al., 2015) & The Church of Santa Maria at Portonovo, Italy & & $\begin{array}{l}\text { Autodesk Revit + plug-in Protégé, } \\
\text { CloudCompare, Cyclone 8.1.3, ReCap }\end{array}$ & $\begin{array}{l}\text { The profiles were designed according to the } \\
\text { measurements extracted from the point cloud }\end{array}$ \\
\hline (Fregonese et al., 2015) & The Galvagnina church, Italy & & $\begin{array}{l}\text { AutoCAD, Autodesk Revit + plug-in } \\
\text { BIM3DGS }\end{array}$ & $\begin{array}{l}\text { The information of each model object is } \\
\text { combined with their 3D model using BIM3DGS }\end{array}$ \\
\hline Baik et al., 2014, 2015) & $\begin{array}{l}\text { Historical Jeddah and the Nasif Historical } \\
\text { House, Saudi Arabia }\end{array}$ & \multirow{2}{*}{ Third category BIM/OSS/and GIS tools } & $\begin{array}{l}\text { Autodesk Revit, Autodesk InfraWorks } \\
\text { platform, Rhinoceros }\end{array}$ & $\begin{array}{c}\text { Creates a special library (JHBIM). Integrates } \\
\text { BIM with GIS }\end{array}$ \\
\hline Dore \& Murphy, 2012 & Is an 18 th century Georgian street, Ireland & & $\begin{array}{l}\text { SketchUp + CityGML plugin, Graphisoft } \\
\text { ArchiCAD, }\end{array}$ & $\begin{array}{l}\text { Create sections and levels on the point cloud. } \\
\text { Also, use historical data to create the model. }\end{array}$ \\
\hline (San Jose et al., 2013) & $\begin{array}{l}\text { Several types of very damaged heritage } \\
\text { buildings in Castilla y León, Spain }\end{array}$ & $\begin{array}{l}\text { Fourth category/OSS/AUX/GIS/non } \\
\text { BIM tools }\end{array}$ & $\begin{array}{l}\text { GIS adapted to the open standard } \\
\text { CityGML, WebGL, e-Learning, MACE, } \\
\text { AVT, ATRAECOM }\end{array}$ & $\begin{array}{l}\text { They have developed a new open source } \\
\text { software platform for e-Learning that facilitates } \\
\text { the tasks of Architectural Cultural Heritage } \\
\text { conservation and rehabilitation. }\end{array}$ \\
\hline
\end{tabular}




\subsubsection{First Category: only BIM Methodologies}

In this category, thirteen documents that present case studies to achieve virtual and parametric 3D modeling of the buildings that are analyzed have been studied. From these thirteen documents, ten have adopted the Autodesk Revit software and three the Graphisoft Archicad software to illustrate the implemented methods. In turn, four documents create H-BIM parametric libraries and the other ten only develop the complete parametric model of the analyzed heritage. Despite the BIM tools used and the purpose of their results, the methodologies that are proposed in the most representative documents of this category have particular similarities for performing such actions as cuts, sections, and levels on the acquired point clouds, which allow for the parametric modeling to be accelerated and optimized. Most of the analyzed works do not declare the degree of automation or the diagnostic and management processes implemented.

For Murphy et al. $[15,82,99]$, the process of creating an H-BIM library begins with the 3D modeling of parametric objects through the integration of point clouds, photogrammetry, historical documentation, and Graphisoft Archicad software. File format and data exchange problems are fixed with the script GDL language included in this software. The simple or regular solid objects of the analyzed heritage are modeled using the simple primitives that are provided by the platform. On the other hand, the irregular shapes found from the analyzed heritage monuments are modeled in two parts. Primarily, a series of sections made on the point cloud are created to identify the profile of each object and the surfaces are subsequently converted to solid elements through NURBS, mesh, and Boolean operations (included in the GDL).

The methodologies that are implemented in these approaches increases the speed of the parametric modeling of the analyzed heritage. However, they do not accurately develop the steps to segment the point clouds, generating confusion in the different conservators who try to implement this architectural modeling process.

The above is also acknowledged in the article by López et al., 2017 [100], in which a three-step methodology is developed to create an H-BIM library of the Romanesque church of Santa María la Real de Mave, Palencia, Spain. The first step covers the collection of semantic and spatial information. In the second step, the obtained data are processed and organized for feeding into the BIM Autodesk Revit platform. In the third step, a design of multiple views, cuts, sections, and grids made on the point cloud are created, following the rules and the constructive patterns of the architectural period that the building belongs to.

As in the previous case, the uniform and simple surfaces are modeled using the basic tools of BIM environments. On the other hand, irregular or complex surfaces are modeled in two stages. The first stage starts with the sketch of the current component profile on a 2D work plane. Subsequently, the reference planes, 2D profiles and modeling tools are integrated to create the solid elements in a 3D work environment. The H-BIM Library developed allows the maintenance, management and rehabilitation of historic buildings. In this approach, the semi-automatic implementation is time consuming and it represents a certain weakness.

Such authors as Del Giudice \& Osello, 2013 [101] and Biagini et al., 2016 [102], have also developed a process of virtual modeling in their methodologies based on the design of multiple sections, cuts, levels and grids made on the point cloud. However, they differ from the above-mentioned articles because they present a new approach to the temporal calculation in the Autodesk Revit platform. This approach is effective for the order and control of the architectural heritage restoration and management projects. These documents have not accurately developed the necessary steps to model and manage each parametric object, and neither have H-BIM libraries been developed, which represents a problem and a disadvantage for their implementation.

There are other important works that could be mentioned in this category. Brumana et al., 2013 [103], Fai \& Sydor, 2013 [104], and D'Auria et al., 2014 [105] have all used a similar workflow to link point clouds with the BIM Autodesk Revit platform. Their main topic is to define or to separate the components to be modeled, depending on their typology, hierarchy, and material. This separation 
facilitates the exchange of data between the different virtual modeling software. The authors argue that the lack of flexible tools in BIM generates drawbacks for historic buildings modeling.

Such authors as Ma et al., 2015 [106] Achille et al., 2015 [107], Cheng et al., 2015 [108], and Adami et al., 2016 [109], describe how the modeling of historical components with BIM platforms can help researchers to visualize a representative 3D model, so as to know the real information of each object, as well as its implementation in the maintenance, management, and restoration processes of the monument. These works have not developed a methodological process on virtual modeling, which impedes its implementation by other researchers to create effective workflows.

These publications about BIM modeling for existing buildings, or about $\mathrm{H}$-BIM, have shown that software tools have not yet been developed to automatically convert point clouds into BIM components. In addition, the lack of algorithms to automatically convert the complex shapes of the point clouds into BIM parametric objects is another bottleneck in the field of $\mathrm{CH}$ reconstruction.

Another common limitation or difference in the comparison between the methodologies analyzed is that each one is often designed to highlight the innovation of a particular method over the others, in some cases, provoking gaps in the information that they want to transmit.

\subsubsection{Second Category: BIM, Auxiliary Tools and OSS Methodologies}

Currently, BIM platforms are not able to solve all of the issues that come from the modeling management and the maintenance of the architectural heritage; therefore, the integration of other instruments or auxiliary tools is needed. In this category, a total of twelve documents have been analyzed. From the twelve documents, seven create H-BIM libraries and five do not. In turn, five papers adopted the commercial Autodesk Revit platform in combination with Rhinoceros and its plug-in Non-Uniform Rational Basis-Splines (NURBS); while, the other four adopted the same platform in combination with BIM Open Source Software (OSS), Autodesk AutoCAD, and 3DMax or Blender. On the other hand, two authors combined the commercial BIM platform, Graphisoft Archicad, with OSS, and the application-programming interface (API), while one author combined Autodesk Revit with its API programming interface. The use of external tools for the efficient and accurate modeling of the analyzed building is the differential factor between these categories.

A workflow of the virtual modeling of the Four Courts in Dublin-Ireland, using the architectural historical documents, physical-constructive analysis, and point clouds, is proposed in Dore et al., 2015 [110]. Parametric objects that are created using the Graphisoft Archicad software and the GDL (3D "RULED") function are part of an H-BIM library. This approach proposes two methodologies: The first consists of modeling the elements using the historical documents and the second is designed for the accurate and the efficient modeling of irregular elements.

For the second methodology, a design of multiple sections, cuts, and levels that were made on the point cloud is created with the Graphisoft Archicad software. The sections that were made on the point cloud are diagrammed as closed, sized polygons using lines and arcs, and serve as a guide to the 3D "RULED" function to generate accurate BIM models from the point cloud.

On the other hand, in Nieto et al., 2016 [111], an innovative processing, cataloging, analysis, and identification methodology of the information is proposed, which begins with the creation of a set of grids on the surface under analysis. For this reason, a set of instructions and algorithms that were written in the API of the Graphisoft Archicad software was created in Nieto et al., 2016 [112], so as to accelerate the automatic generation of the standardized vector grids. The resulting grids serve as a basis for the management, delineation, and recording of the information that can be used to develop an efficient, accurate, and parametric representation of the analyzed architectural heritage. This article is suitable for research focused on identifying and cataloging processes of elements.

Other authors, such as Oreni et al., [112-114] and Barazzetti et al., [115,116], argue that BIM software presents limitations for modeling non-standard architectural objects, characteristic of architectural heritage. Therefore, the integration of the Rhinoceros software is proposed to model the architectural components of the analyzed building and to generate the H-BIM library. These authors 
develop a solution that is based on performing profiles on the point cloud from the use of cuts and levels. These cuts and levels serve to interpret and to separate the different profiles extracted from the point cloud into regular or irregular surfaces.

Regular surfaces are modeled with the Revit software tools and irregular ones are modeled thanks to the vector profiles that were made by NURBS curves, a number of algorithms used in the Boolean operations and the Rhinoceros software. The results that were obtained are exported to the Autodesk Revit platform to obtain parametric models that will be part of an H-BIM library.

Another approach for accurately building modeling is presented in Quattrini et al., 2015 [117]. In this approach, a methodology that minimizes the number of steps and accelerates the modeling of the parametric elements through the integration of point clouds with the Autodesk Revit software is developed. In this document, point clouds are considered to be an excellent source of information, and therefore, cuts, sections, and levels are not performed on the point cloud: each component is modeled directly on the point cloud, thus maintaining the quality and accuracy of the obtained data and details.

This approach classifies the point cloud into regular or irregular surfaces. Regular surfaces are modeled with the Autodesk Revit parametric element libraries and complex ones are created in Boundary Representation (B-Rep). Finally, the Open-Source plug-in Protégé is used to facilitate the integration of parametric data with each modeled element.

Other works could also be mentioned in this category, such as Fregonese et al., 2015 [118] or Rodríguez-Moreno et al., 2016 [119]. In these approaches, the integration of point clouds and historical data with a series of specific software (AutoCAD, SketchUP, 3DStudio Max) and a set of Open-Source Software (OSS) (3DReshaper, BIM3DGS) are used to obtain historical virtual models. In addition, the models that were obtained are exported to the Autodesk Revit software to obtain parametric information, thus enabling the resulting model to help manage and conserve existing buildings. In addition, Fregonese et al., 2015 [118] uses the BIM3DSG software for the management and administration of the model.

Another approach that describes the use of parameterization as a process for contributing to the general framework of "Smart heritage" is presented in Rua et al., 2014 [120]. A methodology is proposed consisting of five main phases: data collection, architectural study, data processing, digital modeling, and virtual modeling. Autodesk AutoCAD and ArGIS software are used to process technical and geographical data. On the other hand, Autodesk Revit tools are used to model, manipulate, and adapt families that are located in the BIM library to the project and Blender is the software used for the visualization and interaction between the virtual model and the general public. The resulting model is a database capable of being used for the management of the analyzed $\mathrm{CH}$.

Another author that emerges from the cultural heritage community is Garagnani, 2013 [121]. This author has developed a plug-in called GreenSpider in the Autodesk Revit software API. This plug-in is able to recognize and select the most determinant points of a point cloud and translate them to native reference points in the Revit modeling environment. In addition, GreenSpider has the ability to connect the points and interpolate the vertices through splines, in this way, allowing for explicit parametric representations of the actual captured surfaces to be generated. After its modeling, the components are fed, through IFC, with the semantic and topological metadata that was stored in a BIM file.

The disadvantage of the approaches that were analyzed in this category is that the lack of intelligent algorithms capable of automatically converting point clouds into parametric objects makes the constructive process of irregular components a challenging and time-consuming process. In addition, the architectural elements are modeled on point clouds using intermediate software, which could result in information being lost when exporting the said elements, and therefore in the conception of the building's general perspective. 


\subsubsection{Third Category: BIM, Auxiliary Tools, OSS and GIS Methodologies}

BIM platforms with geometric/semantic and GIS software are combined by five authors to create detailed historical models. All of the documents create H-BIM libraries. In addition, three documents that were adopted Autodesk Revit and Rhinoceros in combination with the GIS Autodesk InfraWorks software, while another paper adopted Autodesk Revit and Graphisoft Archicad in combination with the GIS (SIGEC and SICaR) software, and another combined Graphisoft Archicad with Sketch-up and their CityGML complement.

Baik et al., [122,123] and Baik, 2017 [124] propose integrating point clouds, Islamic historical manuscripts, and the Hijazi architectural patterns with Autodesk Revit platform, Rhinoceros software, and the Autodesk InfraWorks GIS system, in order to achieve a detailed virtual reconstruction of the Jeddah Historic BIM (JHBIM) library. This library has been specifically designed to accelerate the modeling of Jeddah historical monuments.

First, the point cloud is divided into main-parts and sub-parts. Then, the Autodesk Revit software is used to model the simple objects of the project. On the other hand, irregular surfaces are modeled using NURBS tools of Rhinoceros software. Finally, the BIM 3D model and the 3D GIS Autodesk InfraWorks system are integrated to obtain an accurate and detailed virtual model. The methodologies analyzed have some disadvantages: in particular, because the virtual modeling is a time-consuming manual process and the intervention is limited to Islamic architecture.

Oreni, 2013 [125] proposes integrating metric and semantic information that was obtained from the GIS systems (SIGEC and SICaR) and point clouds, with GraphiSoft ArchiCAD and Autodesk Revit platforms, in order to create an H-BIM library that would provide the basis for the restoration, conservation and management of heritage buildings, and also to facilitate the interoperability with other interested conservators. Although GIS are today the most agile tools to collect, manipulate, and manage the different data on buildings, it should be noted that this article does not effectively develop the steps that are required to integrate GIS systems with BIM platforms, making it difficult for researchers to implement this methodology as a guide to obtain 3D virtual models.

Dore \& Murphy, 2012 [93] propose using the GraphiSoft ArchiCAD GDL scripting language to achieve the 3D virtual modeling of the parametric objects. Later, the objects that already exist in the internal library are combined with the modeled elements and a set structure is created that is incorporated into the design of an H-BIM library. Finally, the 3D model can be integrated into a GIS environment (ArcGIS) using Sketch-up, with its CityGML add-in. The resulting model serves as the basis for the analysis and the management of the information required for the maintenance of heritage buildings, as well as to accelerate the modeling process of other historical buildings with a similar architectural style.

Although, in this category, the authors have demonstrated standardization in the performance analysis and development of the parametric elements, the 'receptor scenarios' have shown that for our contribution, the gaps and variety of their implementation can generate disadvantages for modeling a particular building or monument.

\subsubsection{Fourth Category: Methodologies without BIM}

Finally, BIM platforms are not used as a basis for historical heritage modeling, management, and maintenance by some authors, because they consider that the common BIM software is still unable to manage the huge quantities of data coming from laser scans or photogrammetric surveys, which makes the use of external free or open intermediate software tools (F/OSS) inevitable. In these documents, H-BIM libraries have not been developed. In this category, six documents have been analyzed; two adopted Autodesk AutoCAD software and some OSS software as auxiliary tools, while three other authors create their own tool to model the analyzed heritage. In addition, one document has adopted Rhinoceros in combination with the OSS software (BIM3DSG) and the API of the program.

Fassi et al., 2015 [126] have developed a methodology for the historical 3D modeling, using the Rhinoceros NURBS in combination with an OSS (BIM3DSG) and a series of algorithms written in the 
program API. In this approach, the main topic is to develop an (OSS) easy-to-use and easy-to-learn system, where 3D models can be easily visualized and manipulated using any common touch-screen device. The lack of a descriptive methodology about the use and implementation of the new system, as well as the necessity for continuous Internet connection, are the weakest points of this approach.

On the other hand, Soler et al., 2017 [127], have developed software that is based on GIS systems called Agata. This software is capable of storing and managing all kinds of information associated with each modeled architectural heritage element. It uses (eXtensible Markup Language) XML as a data exchange format. In this approach, the main topic is of great interest for the implementation, but the proposed methodology does not accurately develop the operation and utilization of the new software, or their interoperability with other programs.

In their article, Aguilera \& Lahoz, 2010 [128] have developed a flexible and low-cost system for virtual 3D modeling of archaeological sites. In this document, triangulation algorithms that are based on the 2.5 D Delaunay Triangulation approach are used to convert the image into a polygonal mesh model and to automatically model the elements using polygonal boxes. Subsequently, the models are textured using the Z-buffer algorithm. The resulting models can be grouped and directed to the creation of prototypes to encapsulate and reuse any set of objects. The main drawback of this methodology is that it presents difficulties for the 3D modeling of irregular objects.

The approach of San Jose et al., 2013 [129] develops a new software platform for the volumetric visualization of complex architectural objects and their application to the teaching, management, and conservation of architectural heritage. The proposed methodology intends to incorporate the knowledge of experts through an open-source platform that is based on GIS systems. Such authors, such as as Guidi \& Russo, 2011 [130] or Micoli et al., 2013 [131], propose the integration of point clouds and historical documentation with AutoCAD 3D software and OSS tools to increase the real knowledge of a heritage building and support the historical interpretation. First, point clouds are used as a reference for CAD modeling and as a source of direct information. Later, a web application is used to allow for real-time navigation and achieve the access and management of data in a tridimensional context. The resulting model should serve as a 3D data repository.

As in the previous cases, the lack of a detailed methodology to describe the modeling process of each component is a problem and a disadvantage when being used as a guide by other researchers. It is also worth noting that the use of OSS and API has grown significantly in recent years. However, there are no OSS platforms that are able to integrate all of the stages of the documentation and the modeling process of the heritage components. Another disadvantage of this category is that they fail to develop parametric models. Therefore, BIM software would be needed for the parametric modeling of the different architectural components.

\section{Discussion and Conclusions}

In this work, a review of the documentation and accurate modeling of architectural heritage has been presented. The focus has been placed on presenting different alternatives to understand how to apply BIM platforms before starting an architectural heritage restoration project (rather than comparing the different BIM platforms).

The planning and management of conservation and restoration projects could be improved by having access to the virtual model of a historical monument. 3D laser scanners and photogrammetry are used, along with historical bibliographical analysis, to capture the geometry and identity of the analyzed buildings. Unfortunately, the complexity and irregularity of the shapes characterizing historical buildings, and the lack of intelligent algorithms to fully automate the virtual modeling from point clouds, makes the constructive process of parametric components a significantly time-consuming process. However, the currently reviewed approaches demonstrate that combining BIM tools with GIS tools and auxiliary software are an effective solution for managing and modeling graphical (point clouds) and semantic (historical-constructive information) data, in a semi-automatic way. This is possible because these platforms and tools, through the common data structure IFC, allow the 
interoperability of information and communication between the different actors that are involved in architectural heritage rehabilitation, reconstruction, or maintenance processes.

Moreover, it is worth noting that the modeled architectural components will be part of the parametric H-BIM libraries, thanks to the proposed methodologies. The components of this H-BIM library may be adapted to other monuments belonging to the same period and architectural style, thanks to their flexibility. For this reason, the modeled components should have real information about the graphic documentation, the typology, and the main constructive characteristics of the construction period that the building belongs to. In addition, H-BIM virtual models could be used to automatically produce technical documentation that will serve to interpret the different construction elements, as well as the missing ones; these components could also be used to carry out structural, energetic, luminous, and temporal analyses.

The increased use of H-BIM libraries has demonstrated their usefulness by facilitating the interdisciplinary exchange of semantic and geospatial objects/data between experts from different disciplines in the architectural heritage field. Nevertheless, the lack of international H-BIM libraries, the difference and diversity between different architectural periods, and insufficient international collaboration, have limited the potential use of H-BIM.

This review has shown that there is still much to do in this domain, where more research and development should be done to address the ongoing progress of BIM platforms and their relationship to architectural heritage. Future research could focus, for example, on the development of useful plug-ins for creating different kinds of element arrays. To do this, either the corresponding software development kits (SDK) could be used to program the BIM API directly, or tools (such as Dynamo ${ }^{\circledR}$ Autodesk open source software) that facilitate these process could be used, thus expanding the digital world where researchers or experts in the AEC context can interact concerning architectural heritage anytime, anywhere, and with any device.

In addition, other realistic approaches to the future of architectural heritage would be the need to create shape recognition algorithms to automate the parametric reconstruction of entire buildings, directly from the use of point clouds and to avoid routine tasks that are often time-consuming processes. In this context, another important aspect would be the need to create a universal and free-access H-BIM library containing all the information that is useful for architects, designers, archaeologists, historians, engineers, and conservators of architectural heritage.

Author Contributions: F.J.L. is the main contributor of the paper. He has collected information and has focused on the study and analysis of the different BIM and H-BIM approaches, drafting the paper. P.M.L. and J.L. have contributed to the study and analysis of the data capture and processing methodology. Finally, J.G.-G.-B. and E.Z. are the scientific directors of the work. They have leaded the research, they have made the conception and design of the work, and have made the critical revision of the paper, contributing to the analysis and discussion of the results.

Acknowledgments: The authors acknowledge the "Heritage and Restoration" S.L.U. (Palencia, Spain) for its advice and support. This review has received funding from the EU's H2020 Reflective framework program for research and innovation under grant agreement no. 665220.This work was also supported by the Ministry of Science and Innovation, fundamental research project ref. DPI2014-56500-R, and the Junta de Castilla y León ref. VA036U14.

Conflicts of Interest: The authors declare no conflict of interest. The founding sponsors had no role in the design of the study; in the collection, analyses, or interpretation of data; in the writing of the manuscript, or in the decision to publish the results.

\section{References}

1. Vecco, M. A definition of cultural heritage: From the tangible to the intangible. J. Cult. Heritage 2010, 11, 321-324. [CrossRef]

2. Simeone, D.; Cursi, S.; Toldo, I.; Carrara, G. BIM and knowledge management for building heritage. In Proceedings of the 34th Annual Conference of the Association for Computer Aided Design in Architecture, Los Angeles, CA, USA, 23-25 October 2014. 
3. Penttilä, H.; Rajala, M.; Freese, S. Building information modelling of modern historic buildings. In Proceedings of the 25th eCAADe Conference on Predicting the Future, Frankfurt am Main, Germany, 26-29 September 2007.

4. Tomaževič, M.; Lutman, M. Heritage masonry buildings in urban settlements and the requirements of Eurocodes: Experience of Slovenia. Int. J. Archit. Heritage 2007, 1, 108-130. [CrossRef]

5. Gursel, I.; Sariyildiz, S.; Akin, Ö.; Stouffs, R. Modeling and visualization of lifecycle building performance assessment. Adv. Eng. Inform. 2009, 23, 396-417. [CrossRef]

6. Letellier, R.; Eppich, R. (Eds.) Recording, Documentation and Information Management for the Conservation of Heritage Places; Routledge: Abingdon, UK, 2015.

7. Johansson, M.; Roupé, M.; Bosch-Sijtsema, P. Real-time visualization of building information models (BIM). Autom. Constr. 2015, 54, 69-82. [CrossRef]

8. Acierno, M.; Cursi, S.; Simeone, D.; Fiorani, D. Architectural heritage knowledge modelling: An ontology-based framework for conservation process. J. Cult. Heritage 2017, 24, 124-133. [CrossRef]

9. Gómez-García-Bermejo, J.; Zalama, E.; Feliz, R. Automated registration of 3D scans using geometric features and normalized color data. Comput.-Aided Civ. Infrastruct. Eng. 2013, 28, 98-111. [CrossRef]

10. Lerones, P.M.; Vélez, D.O.; Rojo, F.G.; Gómez-García-Bermejo, J.; Casanova, E.Z. Moisture detection in heritage buildings by 3D laser scanning. Stud. Conserv. 2016, 61 (Suppl. 1), 46-54. [CrossRef]

11. Akbarnezhad, A.; Ong, K.C.G.; Chandra, L.R. Economic and environmental assessment of deconstruction strategies using building information modeling. Autom. Constr. 2014, 37, 131-144. [CrossRef]

12. eBIM. Heritage BIM-eBIM [WWW Document]. 2015. Available online: http:/ / ebim.co.uk/heritage-bim/ (accessed on 25 October 2016).

13. Bryde, D.; Broquetas, M.; Volm, J.M. The project benefits of building information modelling (BIM). Int. J. Proj. Manag. 2013, 31, 971-980. [CrossRef]

14. Gray, M.; Gray, J.; Teo, M.; Chi, S.; Cheung, Y.K.F. Building information modelling: An international survey. In Proceedings of the World Building Congress, Brisbane, Queensland, 5-9 May 2013.

15. Murphy, M.; McGovern, E.; Pavia, S. Historic building information modelling (HBIM). Struct. Surv. 2009, 27, 311-327. [CrossRef]

16. Volk, R.; Stengel, J.; Schultmann, F. Building information modeling (BIM) for existing buildings-Literature review and future needs. Autom. Constr. 2014, 38, 109-127. [CrossRef]

17. McArthur, J.J. A building information management (BIM) framework and supporting case study for existing building operations, maintenance and sustainability. Procedia Eng. 2015, 118, 1104-1111. [CrossRef]

18. Arayici, Y.; Counsell, J.; Mahdjoubi, L.; Nagy, G.A.; Dweidar, K.; Hawas, S. (Eds.) Heritage Building Information Modelling; Taylor \& Francis: Abingdon, UK, 2017.

19. ISO Standard. ISO 16739:2013 Industry Foundation Classes (IFC) for Data Sharing in the Construction and Facility Management Industries. International Standard. 2013. Available online: https://www.iso.org/ standard/51622.html (accessed on 10 February 2018).

20. BuildingSMART International. IFC Overview Summary. 2012. Available online: http://www.buildingsmarttech.org/specifications/ifc-overview/ifc-overview-summary (accessed on 19 April 2018).

21. Eastman, C.M.; Teicholz, P.; Sacks, R.; Liston, K. BIM Handbook: A Guide to Building Information Modeling for Owners, Managers, Designers, Engineers and Contractors, 2nd ed.; John Wiley and Sons: Hoboken, NJ, USA, 2011.

22. Ochmann, S.; Vock, R.; Wessel, R.; Leander Evers, H.; Nergård, H.; Törlind, P. Documenting the Changing State of Built Architecture-Software Prototype v1; Durable Architectural Knowledge (DURAARK), 2014; pp. $20-23$. Available online: http:/ /duraark.eu/wp-content/uploads/2014/02/duraark_d4.4.1_final.pdf (accessed on 21 November 2016).

23. Akcamete, A.; Akinci, B.; Garrett, J.H. Potential utilization of building information models for planning maintenance activities. In Proceedings of the international Conference on Computing in Civil and Building Engineering, Nottingham, UK, 30 June-2 July 2010; pp. 151-158.

24. Cheng, J.C.P.; Ma, L.Y. A BIM-based system for demolition and renovation waste quantification and planning. In Proceedings of the 14th International Conference on Computing in Civil and Building Engineering (ICCCBE 2012), Moscow, Russia, 27-29 June 2012.

25. Wong, J.K.W.; Zhou, J. Enhancing environmental sustainability over building life cycles through green BIM: A review. Autom. Constr. 2015, 57, 156-165. [CrossRef] 
26. Heradio, R.; Perez-Morago, H.; Fernandez-Amoros, D.; Cabrerizo, F.J.; Herrera-Viedma, E. A bibliometric analysis of 20 years of research on software product lines. Inf. Softw. Technol. 2016, 72, 1-15. [CrossRef]

27. Bruno, S.; De Fino, M.; Fatiguso, F. Historic Building Information Modelling: Performance assessment for diagnosis-aided information modelling and management. Autom. Constr. 2018, 86, 256-276. [CrossRef]

28. El-Hakim, S.; Gonzo, L.; Voltolini, F.; Girardi, S.; Rrizzi, A.; Remondino, F.; Whiting, E. Detailed 3D Modelling of Castles. Int. J. Archit. Comput. 2007, 5, 200-220.

29. Grussenmeyer, P.; Landes, T.; Voegtle, T.; Ringle, K. Comparison methods of terrestrial laser scanning, photogrammetry and tacheommetry data for recording of cultural heritage buildings. In Proceedings of the International Archives of the Photogrammetry, Remote Sensing and Spatial Information Sciences, Beijing, China, 3-11 July 2008; pp. 213-218.

30. Furukawa, Y.; Curless, B.; Seitz, S.M.; Szeliski, R. Reconstructing building interiors from images. In Proceedings of the IEEE 12th International Conference on Computer Vision, Kyoto, Japan, 29 September-2 October 2009; pp. 80-87.

31. Klein, L.; Li, N.; Becerik-Gerber, B. Imaged-based verification of as-built documentation of operational buildings. Autom. Constr. 2012, 21, 161-171. [CrossRef]

32. Aicardi, I.; Chiabrando, F.; Lingua, A.M.; Noardo, F. Recent trends in cultural heritage 3D survey: The photogrammetric computer vision approach. J. Cult. Heritage 2018. [CrossRef]

33. Shishido, H.; Ito, Y.; Kawamura, Y.; Matsui, T.; Morishima, A.; Kitahara, I. Proactive preservation of world heritage by crowdsourcing and 3D reconstruction technology. In Proceedings of the 2017 IEEE International Conference on Big Data, Boston, MA, USA, 11-14 December 2017; p. 4426.

34. Tapponi, O.; Kassem, M.; Kelly, G.; Dawood, N.; White, B. Renovation of Heritage Assets using BIM: A Case Study of the Durham Cathedral. In Proceedings of the 32nd CIB W78 Conference, Eindhoven, The Netherlands, 27-29 October 2015.

35. Martín Lerones, P.; Llamas Fernández, J.; Melero Gil, A.; Gómez García-Bermejo, J.; Zalama Casanova, E. A Practical Approach to Making Accurate 3D Layouts of Interesting Cultural Heritage Sites through Digital Models. J. Cult. Heritage 2010, 11, 1-9. [CrossRef]

36. Dore, C.; Murphy, M. Current State of the Art Historic Building Information Modelling. Int. Arch. Photogramm. Remote Sens. Spat. Inf. Sci. 2017, 42, 185-192. [CrossRef]

37. Alsadik, B.; Gerke, M.; Vosselman, G. Automated camera network design for of cultural heritage objects. J. Cult. Heritage 2013, 14, 515-526. [CrossRef]

38. Golparvar-Fard, M.; Bohn, J.; Teizer, J.; Savarese, S.; Peña-Mora, F. Evaluation of image-based modeling and laser scanning accuracy for emerging automated performance monitoring techniques. Autom. Constr. 2011, 20, 1143-1155. [CrossRef]

39. Baselga, S.; Garrigues, P.; Berné, J.L.; Anquela, A.B.; Martín, A. Deformation monitoring in historic buildings: A case study. Surv. Rev. 2011, 43, 484-492. [CrossRef]

40. Mahdjoubi, L.; Moobela, C.; Laing, R. Providing real-estate services through the integration of 3D laser scanning and building information modelling. Comput. Ind. 2013, 64, 1272-1281. [CrossRef]

41. Mukupa, W.; Roberts, G.W.; Hancock, C.M.; Al-Manasir, K. A review of the use of terrestrial laser scanning application for change detection and deformation monitoring of structures. Surv. Rev. 2017, 49, 99-116. [CrossRef]

42. Besl, P.J.; McKay, N.D. A method for registration of 3-D shapes. IEEE Trans. Pattern Anal. Mach. Intell. 1992, 14, 239-256. [CrossRef]

43. Innovmetric. PolyWorks Modeler TM. Available online: https://www.innovmetric.com/en/products/ polyworks-modeler (accessed on 19 April 2018).

44. Remondino, F.; El-Hakim, S.F. Image-Based 3D Modelling: A Review. Photogramm. Rec. J. 2006, $21,269-291$. [CrossRef]

45. Cera, V.; Campi, M. Evaluating the Potential of Imaging Rover for Automatic Point Cloud Generation. Int. Arch. Photogramm. Remote Sens. Spat. Inf. Sci. 2017, XLII-2/W, 147-154. [CrossRef]

46. Pritchard, D.; Sperner, J.; Hoepner, S.; Tenschert, R. Terrestrial laser scanning for heritage conservation: The Cologne Cathedral documentation project. ISPRS Ann. Photogramm. Remote Sens. Spat. Inf. Sci. 2017, 4, 213-220. [CrossRef]

47. Guidi, G.; Russo, M.; Angheleddu, D. 3D survey and virtual reconstruction of archeological sites. Digit. Appl. Archaeol. Cult. Heritage 2014, 1, 55-69. [CrossRef] 
48. Lo Turco, M.; Santagati, C.; Parrinello, S.; Valenti, G.M.; Inzerillo, L. BIM e beni architettonici: Verso una metodologia operativa per la conoscenza e la gestione del patrimonio culturale-BIM and architectural heritage: Towards an operational methodology for the knowledge and the management of Cultural Heritage. Disegnare con 2016, 9, 161-169.

49. Tang, P.; Huber, D.; Akinci, B.; Lipman, R.; Lytle, A. Automatic reconstruction of as-built building information models from laser-scanned point clouds: A review of related techniques. Autom. Constr. 2010, 19, 829-843. [CrossRef]

50. Jung, J.; Hong, S.; Jeong, S.; Kim, S.; Cho, H.; Hong, S.; Heo, J. Productive modeling for development of as-built BIM of existing indoor structures. Autom. Constr. 2014, 42, 68-77. [CrossRef]

51. Hong, S.; Jung, J.; Kim, S.; Cho, H.; Lee, J.; Heo, J. Semi-automated approach to indoor mapping for 3D as-built building information modeling. Comput. Environ. Urban Syst. 2015, 51, 34-46. [CrossRef]

52. Wang, C.; Cho, Y.K.; Kim, C. Automatic BIM component extraction from point clouds of existing buildings for sustainability applications. Autom. Constr. 2015, 56, 1-13. [CrossRef]

53. Zheliazkova, M.; Naboni, R.; Paoletti, I. A parametric-assisted method for 3D generation of as-built BIM models for the built heritage. WIT Trans. Built Environ. 2015, 153, 693-704.

54. Liu, Y. Robust segmentation of raw point clouds into consistent surfaces. Sci. China Technol. Sci. 2016, 59, 1156-1166. [CrossRef]

55. MeshLab. Description. Available online: http://www.meshlab.net/\#description (accessed on 19 April 2018).

56. Amano, K.; Lou, E. BIM for existing facilities: Feasibility of spectral image integration to 3D point cloud data. In Proceedings of the MATEC Web of Conferences-The 4th International Building Control Conference, Kuala Lumpur, Malaysia, 7-8 March 2016; pp. 1-5. [CrossRef]

57. Pu, S.; Vosselman, G. Knowledge based reconstruction of building models from terrestrial laser scanning data. ISPRS J. Photogramm. Remote Sens. 2009, 64, 575-584. [CrossRef]

58. Dore, C.; Murphy, M. Semi-automatic modelling of building facades with shape grammars using historic building information modelling. ISPRS Int. Arch. Photogramm. Remote Sens. Spat. Inf. Sci. 2013, 40, 5. [CrossRef]

59. ClearEdge 3D (2011) EdgeWise Plant Suite I ClearEdge 3D. Available online: http:/ / www.clearedge3d.com/ products/edgewise-plant-suite/ (accessed on 11 February 2018).

60. Logothetis, S.; Karachaliou, E.; Stylianidis, E. From OSS CAD to BIM for cultural heritage digital representation. The International Archives of the Photogrammetry, Remote Sensing and Spatial Information Sciences. In Proceedings of the 3D Virtual Reconstruction and Visualization of Complex Architectures, Nafplio, Greece, 1-3 March 2017; pp. 1-3.

61. Scan-to-BIM. 2014. IMAGINiT, Scan to Bim. Available online: http://www.imaginit.com/software/imaginitsoftware-other-products/scan-to-bim (accessed on 14 February 2018).

62. Bianchini, C.; Borgogni, F.; Ippolito, A.; Senatore, L.J. The Surveying and Representation Process Applied to Archaeology: A Quest for Invariants in a Highly Variable Context. In Computational Modeling of Objects Presented in Images Fundamentals, Methods and Applications; Paolo, D.G., Daniela, I., Natal Jorge Renato, R.S., Tavares, J.M., Eds.; Springer International Publishing: Berlin, Germany, 2014; Volume 15, pp. 1-29. ISBN 978-3-319-04038.

63. Bianchini, C. Survey, modeling, interpretation as multidisciplinary components of a Knowledge System. SCIRES-IT 2014, 4, 15-24.

64. Giel, B.; Issa, R.R.A. Using laser scanning to access the accuracy of as-built BIM. In Proceedings of the International Workshop on Computing in Civil Engineering, Miami, FL, USA, 19-22 June 2011; pp. 665-672.

65. Pezeshki, Z.; Ivari, S.A.S. Applications of BIM: A Brief Review and Future Outline. Arch. Comput. Methods Eng. 2016, 1, 40. [CrossRef]

66. Watson, A. Digital buildings-Challenges and opportunities. Adv. Eng. Inform. 2011, 25, 573-581. [CrossRef]

67. Bozoglu, J. Collaboration and coordination learning modules for BIM education. J. Inf. Technol. Constr. 2016, 21, 152-163.

68. Pauwels, P.; Verstraeten, R.; De Meyer, R.; Van Campenhout, J. Architectural information modelling for virtual heritage application. In Proceedings of the International Conference on Virtual Systems and Multimedia (VSMM), Brisbane, Australia, 23-26 September 2008; pp. 18-23.

69. Logothetis, S.; Delinasiou, A.; Stylianidis, E. Building Information Modelling for Cultural Heritage: A review. ISPRS Ann. Photogramm. Remote Sens. Spat. Inf. Sci. 2015, 2, 177-183. [CrossRef] 
70. Azhar, S. Building information modeling (BIM): Trends, benefits, risks, and challenges for the AEC industry. Leadersh. Manag. Eng. 2011, 11, 241-252. [CrossRef]

71. American Institute of Architects. AIA Contract Document G202-2013. Building Information Modeling Protocol Form. 2013. Available online: http:/ / www.aia.org/digitaldocs (accessed on 17 February 2018).

72. Leite, F.; Akcamete, A.; Akinci, B.; Atasoy, G.; Kiziltas, S. Analysis of modeling effort and impact of different levels of detail in building information models. Autom. Constr. 2011, 20, 601-609. [CrossRef]

73. De Masi, A. From knowledge to complex representation interpretation of material systems, survey guidelines and reading criteria, multi-representations of 3D city models for Cultural Heritage. Digit. Heritage 2015, 2, 133-136.

74. Logothetis, S.; Stylianidis, E. BIM Open Source Software (OSS) for the documentation of cultural heritage. Virtual Archaeol. Rev. 2016, 7, 28-35. [CrossRef]

75. Hosseini, M.R.; Roelvink, R.; Papadonikolaki, E.; Edwards, D.J.; Parn, E. Integrating BIM into facility management: Typology matrix of information handover requirements. Int. J. Build. Pathol. Adapt. 2018. [CrossRef]

76. East, W.E.; Carrasquillo-Mangual, M. "The COBie Guide: A Commentary to the NBIMS-US COBie Standard." (Realase 3); Engineer Research and Development Center: Champaign IL, USA, 2013.

77. Kassem, M.; Kelly, G.; Dawood, N.; Serginson, M.; Lockley, S. BIM in facilities management applications: A case study of a large university complex. Built Environ. Project Asset Manag. 2015, 5, 261-277. [CrossRef]

78. Fai, S.; Graham, K.; Duckworth, T.; Wood, N.; Attar, R. Building information modelling and heritage documentation. In Proceedings of the 23rd International Symposium, International Scientific Committee for Documentation of Cultural Heritage (CIPA), Prague, Czech Republic, 12-19 July 2011; pp. 12-16.

79. Hichri, N.; Stefani, C.; De Luca, L.; Veron, P. REVIEW OF THE « AS-BUILT BIM » APPROACHES. In Proceedings of the 3D-ARCH-3D Virtual Reconstruction and Visualization of Complex Architectures, Trento, Italy, 25-26 February 2013; pp. 107-112.

80. Chevrier, C.; Charbonneau, N.; Grussenmeyer, P.; Perrin, J.P. Parametric documenting of built heritage: 3D virtual reconstruction of architectural details. Int. J. Archit. Comput. 2010, 8, 135-150. [CrossRef]

81. Anil, E.B.; Tang, P.; Akinci, B.; Huber, D. Deviation analysis method for the assessment of the quality of the as-is Building Information Models generated from point cloud data. Autom. Constr. 2013, 35, 507-516. [CrossRef]

82. Murphy, M.; McGovern, E.; Pavia, S. Historic building information modelling-adding intelligence to laser and image based surveys. ISPRS Int Arch. Photogramm. Remote Sens. Spat. Inf. Sci. 2011, 3816, 1-7. [CrossRef]

83. Software ArchiCAD. Graphisoft. Available online: http://www.graphisoftus.com/2014/ (accessed on 21 December 2017).

84. Tekla. Available online: http:/ / www.tekla.com/ (accessed on 21 December 2017).

85. Cheng, Y.M.; Wu, I.C. Parametric BIM Objects Exchange and Sharing between Heterogeneous Systems. In Proceedings of the 30th International Symposium on Automation and Robotics in Construction (ISARC), Montreal, QC, Canada, 11-15 August 2013; pp. 320-328.

86. Bentley. Available online: https://www.bentley.com/en/products/brands/microstation (accessed on 21 December 2017).

87. BuildingSMART (2016). International Home of OpenBIM. Available online: http://buildingsmart.org (accessed on 30 December 2017).

88. Learn about Revit. Help Autodesk REVIT 2015. Available online: http://help.autodesk.com/view/RVT/ 2015/ENU/ (accessed on 3 February 2018).

89. Autodesk Navisworks. Navisworks Knowledge Network. Available online: https:/ /knowledge.autodesk. com/support/navisworks-products (accessed on 3 February 2017).

90. 3D for Everyone. SketchUp. Available online: http://www.sketchup.com (accessed on 3 February 2018).

91. Autodesk Ecotect Analysis. Ecotect Analysis Knowledge Network. Available online: https://knowledge. autodesk.com/support/ecotect-analysis?sort=score (accessed on 3 February 2018).

92. DAYSIM. Engineering Guide. Available online: http://daysim.ning.com/page/program-structure (accessed on 3 February 2017).

93. Dore, C.; Murphy, M. Integration of HBIM and 3D GIS for digital heritage modelling. In Proceedings of the Digital Documentation International Conference, Edinburgh, Scotland, 22-23 October 2012. 
94. Dore, C.; Murphy, M. Semi-Automatic Generation of As-Built BIM Façade Geometry from Laser and Image Data. J. Inf. Technol. Constr. 2014, 19, 20-46.

95. Quattrini, R.; Baleani, E. Theoretical background and historical analysis for 3D reconstruction model. Villa Thiene at Cicogna. J. Cult. Heritage 2015, 16, 119-125. [CrossRef]

96. Quattrini, R.; Pierdicca, R.; Morbidoni, C. Knowledge-based data enrichment for HBIM: Exploring high-quality models using the semantic-web. J. Cult. Heritage 2017, 28, 129-139. [CrossRef]

97. Bianchini, C.; Inglese, C.; Ippolito, A. The role of BIM (Building Information Modeling) for representation and managing of built and historic artifacts. Disegnare con 2016, 9, 10-11.

98. Bianchini, C.; Inglese, C.; Ippolito, A.; Maiorino, D.; Senatore, L.J. Building Information Modeling (BIM): Great Misunderstanding or Potential Opportunities for the Design Disciplines? In Handbook of Research on Emerging Technologies for Digital Preservation and Information Modeling; IGI Global: Hershey, PA, USA, 2017; pp. 67-90.

99. Murphy, M.; McGovern, E.; Pavia, S. Historic building information modelling-Adding intelligence to laser and image based surveys of European classical architecture. ISPRS J. Photogram. Remote Sens. 2013, 76, 89-102. [CrossRef]

100. López, F.J.; Lerones, P.M.; Llamas, J.; Gómez-García-Bermejo, J.; Zalama, E. A Framework for Using Point Cloud Data of Heritage Buildings Toward Geometry Modeling in A BIM Context: A Case Study on Santa Maria La Real De Mave Church. Int. J. Archit. Heritage 2017, 11, 965-986. [CrossRef]

101. Del Giudice, M.; Osello, A. BIM for cultural heritage. Int. Arch. Photogramm. Remote Sens. Spat. Inf. Sci. 2013, 40, 225-229. [CrossRef]

102. Biagini, C.; Capone, P.; Donato, V.; Facchini, N. Towards the BIM implementation for historical building restoration sites. Autom. Constr. 2016, 71, 74-86. [CrossRef]

103. Brumana, R.; Oreni, D.; Raimondi, A.; Georgopoulos, A.; Bregianni, A. From survey to HBIM for documentation, dissemination and management of built heritage: The case study of St. Maria in Scaria d'Intelvi. Digit. Heritage Int. Congr. 2013, 1, 497-504.

104. Fai, S.; Sydor, M. Building Information Modelling and the documentation of architectural heritage: Between the 'typical'and the 'specific'. Digit. Heritage Int. Congr. 2013, 1, 731-734.

105. D'Auria, S.; De Feo, E.; Di Ruocco, G. Parametric planning for the restoration and rehabilitation of architectural heritage. CSE-City Saf. Energy 2014, 2, 107-118.

106. Ma, Y.P.; Hsu, C.C.; Lin, M.C.; Tsai, Z.W.; Chen, J.Y. Parametric Workflow (BIM) for the Repair Construction of Traditional Historic Architecture in Taiwan. Int. Arch. Photogramm. Remote Sens. Spat. Inf. Sci. 2015, 40, 315-322. [CrossRef]

107. Achille, C.; Lombardini, N.; Tommasi, C. BIM and cultural heritage: Compatibility tests in an archaeological site. WIT Trans. Built Environ. 2015, 149, 593-604. [CrossRef]

108. Cheng, H.M.; Yang, W.B.; Yen, Y.N. BIM applied in historical building documentation and refurbishing. Int. Arch. Photogramm. Remote Sens. Spat. Inf. Sci. 2015, 40, 85-90. [CrossRef]

109. Adami, A.; Chiarini, S.; Cremonesi, S.; Fregonese, L.; Taffurelli, L.; Valente, M.V. The Survey of Cultural Heritage after an Earthquake: The Case of Emilia-Lombardia in 2012. ISPRS-Int. Arch. Photogramm. Remote Sens. Spat. Inf. Sci. 2016, XLI-B5, 161-168. [CrossRef]

110. Dore, C.; Murphy, M.; McCarthy, S.; Brechin, F.; Casidy, C.; Dirix, E. Structural simulations and conservation analysis-Historic building information model (HBIM). Int. Arch. Photogramm. Remote Sens. Spat. Inf. Sci. 2015, 40, 351-357. [CrossRef]

111. Nieto, J.E.; Moyano, J.J.; Delgado, F.R.; García, D.A. Management of built heritage via HBIM Project: A case of study of flooring and tiling. Virtual Archaeol. Rev. 2016, 7, 1-12. [CrossRef]

112. Oreni, D.; Brumana, R.; Della Torre, S.; Banfi, F.; Previtali, M. Survey turned into HBIM: The restoration and the work involved concerning the Basilica di Collemaggio after the earthquake (L'Aquila). ISPRS Ann. Photogramm. Remote Sens. Spat. Inf. Sci. 2014, 2, 267-273. [CrossRef]

113. Oreni, D.; Brumana, R.; Georgopoulos, A.; Cuca, B. HBIM for conservation and management of built heritage: Towards a library of vaults and wooden bean floors. ISPRS Ann. Photogramm. Remote Sens. Spat. Inf. Sci. 2013, 5, 215-221. [CrossRef]

114. Oreni, D.; Brumana, R.; Banfi, F.; Bertola, L.; Barazzetti, L.; Cuca, B.; Roncoroni, F. Beyond Crude 3D Models: From Point Clouds to Historical Building Information Modeling via NURBS; EuroMed: Limassol, Cyprus, 3-8 November 2014; pp. 166-175. 
115. Barazzetti, L.; Banfi, F.; Brumana, R.; Gusmeroli, G.; Oreni, D.; Previtali, M.; Schiantarelli, G. BIM from laser clouds and finite element analysis: Combining structural analysis and geometric complexity. Int. Arch. Photogramm. Remote Sens. Spat. Inf. Sci. 2015, 40, 345. [CrossRef]

116. Barazzetti, L.; Banfi, F.; Brumana, R.; Previtali, M.; Roncoroni, F. BIM from laser scans ... not just for buildings: NURBS-based parametric modeling of a medieval bridge. ISPRS Ann. Photogramm. Remote Sens. 2016, 5, 51-56. [CrossRef]

117. Quattrini, R.; Malinverni, E.S.; Clini, P.; Nespeca, R.; Orlietti, E. From TLS to HBIM. High quality semantically-aware 3D modeling of complex architecture. Int. Arch. Photogramm. Remote Sens. Spat. Inf. Sci. 2015, 40, 367. [CrossRef]

118. Fregonese, L.; Achille, C.; Adami, A.; Fassi, F.; Spezzoni, A.; Taffurelli, L. BIM: An integrated model for planned and preventive maintenance of architectural heritage. Digit. Heritage 2015, 2, 77-80.

119. Rodríguez-Moreno, C.; Reinoso-Gordo, J.F.; Rivas-López, E.; Gómez-Blanco, A.; Ariza-López, F.J.; Ariza-López, I. From point cloud to BIM: An integrated workflow for documentation, research and modelling of architectural heritage. Surv. Rev. 2016, 1-20. [CrossRef]

120. Rua, H.; Gil, A. Automation in heritage-Parametric and associative design strategies to model inaccessible monuments: The case-study of eighteenth-century Lisbon Águas Livres Aqueduct. Digit. Appl. Archaeol. Cult. Heritage 2014, 1, 82-91. [CrossRef]

121. Garagnani, S. Building Information Modeling and real world knowledge: A methodological approach to accurate semantic documentation for the built environment. Digit. Heritage Int. Congr. 2013, 1, 489-496.

122. Baik, A.; Alitany, A.; Boehm, J.; Robson, S. Jeddah Historical Building Information Modelling JHBIM-Object Library. ISPRS Ann. Photogramm. Remote Sens. Spat. Inf. Sci. 2014, 2, 41. [CrossRef]

123. Baik, A.; Yaagoubi, R.; Boehm, J. Integration of Jeddah Historical BIM and 3D GIS for Documentation and Restoration of Historical Monument. Int. Arch. Photogramm. Remote Sens. Spat. Inf. Sci. 2015, 40, 29. [CrossRef]

124. Baik, A. From point cloud to jeddah heritage BIM nasif historical house-case study. Digit. Appl. Archaeol. Cult. Heritage 2017, 4, 1-18. [CrossRef]

125. Oreni, D. From 3D Content Models to HBIM for Conservation and Management of Built Heritage. In Proceedings of the 13th International Conference of Science and Computation ICCSA, Ho Chi Minh City, Vietnam, 24-27 June 2013; Springer: Berlin/Heidelberg, Germany, 2013; Volume 7974, pp. 344-357.

126. Fassi, F.; Achille, C.; Mandelli, A.; Rechichi, F.; Parri, S. A New Idea of Bim System for Visualization, Web Sharing and Using Huge Complex 3d Models for Facility Management. Int. Arch. Photogramm. Remote Sens. Spat. Inf. Sci. 2015, 40, 359-366. [CrossRef]

127. Soler, F.; Melero, F.J.; Luzón, M.V. A complete 3D information system for cultural heritage documentation. J. Cult. Heritage 2017, 23, 49-57. [CrossRef]

128. Aguilera, D.G.; Lahoz, J.G. Virtual archaeological sites modelling through low-cost methodology. Surv. Rev. 2010, 42, 300-315. [CrossRef]

129. San Jose, J.I.; Martinez, J.; Alvarez, N.; Fernández, J.; Delgado, F.; Martinez, R.; Finat, J. An open source software platform for visualizing and teaching conservation tasks in architectural heritage environments. In Proceedings of the XXIV International CIPA Symposium, Strasbourg, France, 2-6 September 2013; pp. 367-372.

130. Guidi, G.; Russo, M. Reality-based and reconstructive models: Digital media for cultural heritage valorization. SCIRES-IT 2011, 1, 71-86.

131. Micoli, L.; Guidi, G.; Angheleddu, D.; Russo, M. A multidisciplinary approach to 3D survey and reconstruction of historical buildings. Digit. Heritage Int. Congr. 2013, 2, 241-248.

(C) 2018 by the authors. Licensee MDPI, Basel, Switzerland. This article is an open access article distributed under the terms and conditions of the Creative Commons Attribution (CC BY) license (http:/ / creativecommons.org/licenses/by/4.0/). 